\title{
Immunological Techniques for Studies on the Biogenesis of Mitochondrial Membrane Proteins
}

\author{
Sigurd Werner and Walter Sebald Institut für Physiologische Chemie, \\ Physikalische Biochemie und Zellbiologie der Universität München and Gesellschaft für \\ Biotechnologische Forschung mbH, Braunschweig-Stöckheim, Germany
}

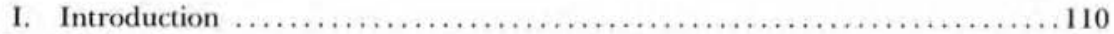

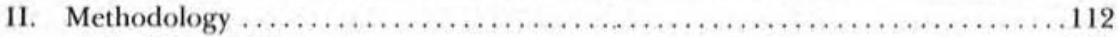

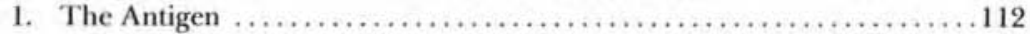

A. Isolation of Mitochondrial Membrane Proteins $\ldots \ldots \ldots \ldots \ldots \ldots \ldots 112$

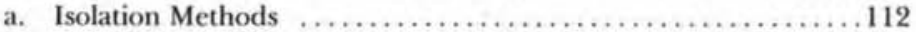

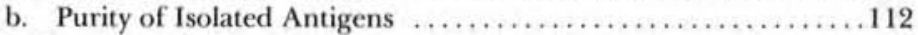

B. Radioactive Labeling of Mitochondrial Proteins in vivo . .........113

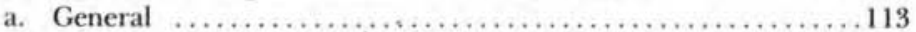

b. Labeling Procedures by in vivo Incorporation of

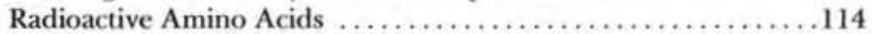

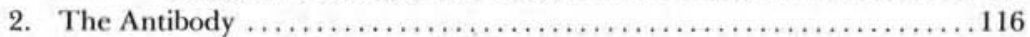

A. Production and Preparation of Antiserums ................. 116

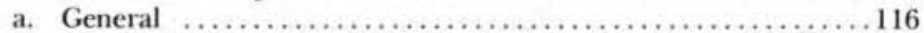

b. Preparation of Immunogens ........................ 117

c. Injection of Animals ............................. 117

d. Collecting Blood ............................... 118

e. Separation of Serum .............................. 119

B. Purification of the Antibody . .......................... 119

a. Serum Fractionation with Ammonium Sulfate ............... 119

b. DEAE-Cellulose Chromatography ..................... 120

c. Isolation of Monospecific Antibodies ................... 120

3. The Antibody-Antigen Reaction ............................ 122

A. Solubilization of Mitochondrial Membrane Proteins .............. 122

B. Precipitation Reaction in Gels ........................... 123

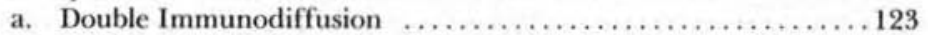

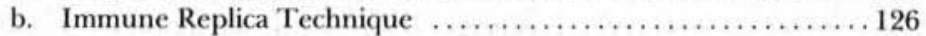

c. Crossed Immunoelectrophoresis ...................... 127

d. Other Techniques ................................ 127

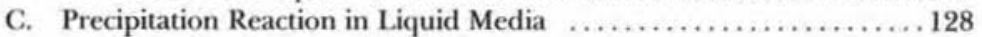

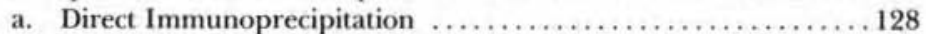

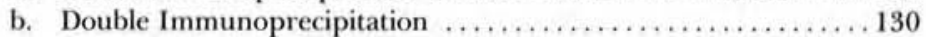

c. Support Fixed Antibodies ............................ 130

d. Analysis of the Antibody-Antigen Complex ................. 132 
III. Application of Immunoreactions for Biogenetic Studies on Mitochondrial

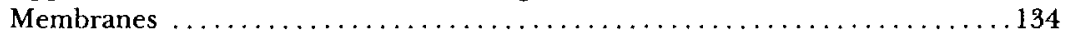

1. Specific Content of Defined Membrane Components in Mitochondria . . 134

2. Assessment of Precursor Pools of Cytochrome Oxidase ............ 135

3. Site of Translation of Mitochondrial Polypeptides ............... 139

4. Isolation of Precursors of Cytochrome Oxidase in Wild-Type and in Cytochrome Oxidase Deficient Cells . . . . . . . . . . . . . . . . 147

5. Identification of Assembly Intermediates of Cytochrome Oxidase ... 156

6. Import of Proteins into the Mitochondria $\ldots \ldots \ldots \ldots \ldots \ldots \ldots \ldots \ldots$

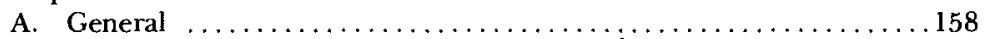

B. Precursor of an Intrinsic Membrane Protein: the ATPase Proteolipid from Neurospora crassa $\ldots \ldots \ldots \ldots \ldots \ldots \ldots \ldots \ldots . \ldots 159$

C. A Peripheral Membrane Protein Functioning at the Outer Surface of the Inner Mitochondrial Membrane: Biosynthesis of Cytochrome $c$ of Neurospora crassa ..............................161

D. A Peripheral Membrane Protein Functioning at the Inner Surface of the Inner Mitochondrial Membrane: Biosythesis of the Multisubunit $\mathbf{F}_{\mathbf{1}}$-ATPase of Baker's Yeast

E. Regulation of Mitochondrial Protein Synthesis by Cytoplasmic Precursor Proteins . . . . . . . . . . . . . . . . . . . . . . . 164

7. Identification of Mitochondrial $m$ RNA and of Mitochondrial Structural

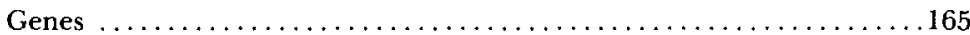

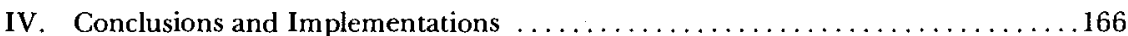

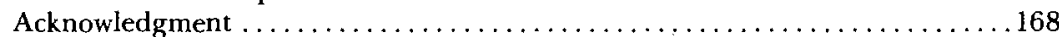

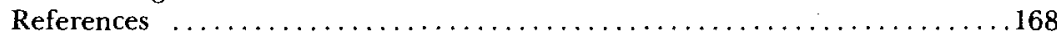

\section{INTRODUCTION}

Knowledge about the biogenesis of mitochondria has increased considerably in recent years. This increase was made possible mainly by two interrelated events: (1) A number of mitochondrial membrane proteins have been purified to near homogeneity. These protein preparations meet the standards set by biochemists interested in protein sequencing, immunological analyses, or both. (2). It was found that immunological partner molecules react with high specificity in the presence of so-called "mild detergents." This led to the introduction of a large variety of antibody techniques into that field.

The advantages of exploiting immunological systems for the detection, isolation, and characterization of proteins can be briefly described by three key terms: specificity, sensitivity, and rapidity. For these features to be profitable when analyzing constituents of such complex structures as mitochondrial membranes, most "classical" immunological techniques must be adapted to meet special requirements. Consequently, the first part of this chapter outlines the methodology of 
immunochemical reactions applied to biogenetic studies. It has not been the aim of the authors to review all of the useful techniques elaborated for the isolation of mitochondrial antigens. Rather, we shall describe a limited number of methods which, we believe, can tackle most biogenetic problems. Emphasis has been placed on explaining experimental difficulties and possible sources of artifacts and demonstrating the potentials and limitations of various methods. Some sections, for instance those dealing with the preparation of the antibody, have been covered superficially, since the applied techniques agree largely with those described in the standard immunological literature which might be consulted for further information. On the other hand, the material offered may facilitate experiments by investigators inexperienced in immunological techniques.

Special attention has been devoted to radioactive labeling procedures. Although not an immunological technique per se, the labeling of mitochondrial proteins not only greatly enhances the sensitivity of the antibody assays used-for example, minor amounts of mitochondrial membrane components now become detectable-but it also makes possible, with the aid of specific inhibitors of the protein synthesis, a selective labeling, and hence the identification of proteins of different translational origin. Absolutely indispensible is the isotope labeling of mitochondrial proteins in order to study the formation of a functional membrane unit by following the route of the involved polypeptides from their translation site to their final site in the organelle. The methodical interdependency between the detection system (incorporation of the radioactive label into the proteins), the isolation system (application of specific antibodies), and the identification system (gel electrophoretic analysis of the isolated material) yields experimental answers of the biogenetic questions.

This is what we have tried to demonstrate in the second part of the chapter. Here again we do not review the many experiments performed with various organisms, but we have selected a number of illustrative experiments, which ought to clarify how the methodology is transformed into biogenetic answers. On one hand, the examples employed should outline the potential of the complete experimental approaches, and on the other, they should serve as a basis for a critical discussion of the validity of the results obtained. This implies that a rather detailed description of the experimental conditions has been provided. For this reason, we have reported on experiments done with Neurospora crassa, the organism that we have chosen in our laboratories for biogenetic studies on mitochondria. 


\section{METHODOLOGY}

\section{The Antigen}

\section{A. ISOLATION OF MITOGHONDRIAL MEMBRANE PROTEINS}

A variety of components, such as proteins, lipids, and pigments are required for the assembly of mitochondrial membranes. Although phospholipids such as cardiolipin and components like the hemes may be included in future immunological approaches, we concentrate in this chapter exclusively on the "classical mitochondrial antigens," the proteins.

a. Isolation Methods. The membrane proteins are usually classified roughly into two groups: (1) the intrinsic membrane proteins, and (2) the extrinsic or membrane-associated proteins. The proteins of the latter category are easily separated from the other membrane components by ultrasonic treatment, by high salt extraction of mitochondrial membranes, or both. The released material is recovered in a genuine aqueous solution. As such, these proteins can be isolated by standard biochemical techniques. A typical example is the purification of cytochrome $c$ (see Brautigan et al., 1978). On the other hand, the preparation of intrinsic membrane proteins requires the application of detergents or organic solvents to solubilize the components. The most frequently used isolation techniques in this field are: ammonium sulfate fractionation in the presence of bile acids, for example, cytochrome oxidase, succinate coenzyme $Q$ reductase, cytochrome $b c_{1^{-}}$ complex, and cytochrome $c_{1}$ (for recent contributions see Fleischer and Packer, 1978); chromatography on hydrophobic substituted resins in the presence of bile acids [cytochrome $b$ (Weiss, 1972) and cytochrome oxidase (Weiss et al., 1971)]; affinity chromatography on immobilized cytochrome $c$ [cytochrome $b c_{1}$-complex (Weiss and Juchs, 1978)]; adsorption chromatography on hydroxylapatite in the presence of Triton [ADP/ATP translocator (Riccio et al., 1975), cytochrome $b c_{1}$-complex (Jagow et al., 1977), cytochrome $b$ (Jagow et al., 1978)]; and extraction with organic solvents [e.g., dicyclohexylcarbodiimide-binding subunit of ATPase (Cattell et al., 1971; Sierra and Tzagoloff, 1973; Sebald et al., 1979a)]. Polypeptide subunits of oligomeric membrane proteins are usually obtained by treating the isolated complexes with depolymerizing agents. The subsequent separation technique depends largely on the solubility of the individual polypeptide component.

b. Purity of Isolated Antigens. An antigen-antibody reaction is considered to be specific as long as one of its partners is pure. Since in 
most biogenetic studies of mitochondria involving antibodies, extracts of mitochondrial membranes, of crude mitochondrial preparations, or even of whole cells are employed as the antigen source, the specificity of the reaction depends strongly on the properties of the antibodies. This calls for the use of specific antibody which recognizes only one defined protein species in the extract. A prerequisite for the production of such a specific tool, however, is the availability of a highly purified antigen. Any contamination of the mitochondrial protein preparation can be considered as an additional immunogen which may lead to the production of a polyspecific antiserum, a tool of limited experimental value.

Generally acceptable criteria for the purity of a mitochondrial membrane protein are difficult to assign. Membrane proteins of known function, such as enzymes, may be defined provisionally as the smallest unit exhibiting a defined substrate-specific reaction. Information about the specific binding of an inhibitor to the protein, about the presence of prosthetic groups, or about the presence of metal ions, greatly facilitates the characterization of membrane constitutents. The polypeptide composition of a supramolecular protein complex is usually examined by polyacrylamide gel electrophoresis in the presence of dodecylsulfate. Preparations found to "consist of only one band" using this electrophoretic technique, may be subjected to additional analytical procedures, such as isoelectric focusing and determination of the $N$-terminal residue.

\section{B. RADIOACTIVE LABELING OF MITOCHONDRIAL PROTEINS in vivo}

a. General. One of the most important techniques for biogenetic studies is the in vivo labeling of mitochondria by the incorporation of radioactive precursor components into the membrane proteins. Usually labeled amino acids are applied, but other labeled components, for example $\delta$-aminolevulinic acid, sulfate, or heavy metal ions may be considered in special cases.

Incorporation experiments on mitochondria have been performed predominantly on rapidly growing organisms such as yeast and fungi, as well as HeLa cells (for review see Buetow and Wood, 1978). Similar labeling procedures have successfully been applied to mammalian tissues exhibiting relatively low rates or protein synthesis, such as isolated rat liver cells (Ries et al., 1978).

In the following paragraph some relevant in vivo labeling techniques of mitochondrial proteins are detailed using Neurospora crassa. This mold has the advantage of growing in a liquid medium containing only 
salts (minimal medium) and sugar as a carbon source. Amino acids added to the culture are transported into the cells rapidly and nearly quantitatively (Schwab et al., 1972). We usually prefer leucine as the radioactive label, since it has been shown that this amino acid is not reutilized by the cells (Schwab, 1973). Moreover, no measureable turnover of mitochondrial proteins takes place during the applied labeling periods (Schwab et al., 1972).

\section{b. Labeling Procedures by in vivo Incorporation of Radioactive Amino Acids}

Pulse-labeling. Exponentially growing cells of Neurospora crassa can be pulse-labeled with radioactive leucine when the amount of amino acids added to the culture is comparable to the intracellular leucine pool of the cells (2 to $4 \mu \mathrm{mole} / \mathrm{g}$ of cellular protein) (Schwab et al., 1972; Sebald et al., 1979b; Hallermayer et al., 1977). Labeling of total cellular protein is complete after 5 to $10 \mathrm{~min}$. Shorter labeling periods are implemented by the application of a chase: cold leucine is added to the culture to arrive at a final concentration of $1 \mathrm{~m} M$.

The radioactivity occurs first in precursor proteins, and appears after a certain time in the end products, depending on the individual pool sizes of the precursors (see Section III.2). In the case of cytochrome oxidase (Schwab et al., 1972; Sebald et al., 1973; Werner, 1974), cytochrome $b$ (Weiss and Ziganke, 1974; Weiss, 1976), and the ATPase complex (Sebald, 1977), 60 to 120 min are necessary until all radioactivity appears in the "mature" protein.

Uniform labeling. The amount of label observed in all "mature" proteins is fairly uniform (homogeneous), because a constant protein pattern is maintained during exponential growth, and thus the synthetic rate of a given protein is proportional to its cellular content.

After the uniform labeling, the specific radioactivity of the total cell protein can be calculated:

$$
\mathrm{dpm} / \mathrm{mg} \text { protein }=\frac{\mathrm{dpm}(\text { leucine }) \text { added to the culture }}{\mathrm{mg} \text { protein per culture }}
$$

The specific radioactivity of individual proteins definitely depends on their leucine contents. In most cases, however, the actual activity observed is very similar to the average obtained for the total cellular protein.

An 18-hr culture of Neurospora crassa usually contains $10 \mathrm{~g}$ wet weight of cells per liter, which corresponds to about $0.5 \mathrm{~g}$ of cellular protein. 
When $50 \mu \mathrm{Ci}\left[{ }^{14} \mathrm{C}\right]$ leucine are added to one liter of a 15-hr-old culture, the uniform labeling of the protein obtained $3 \mathrm{hr}$ later will therefore amount to about $200 \times 10^{3} \mathrm{dpm} / \mathrm{mg}$. For the isolation of mitochondrial proteins immunologically, aliquots of 50 to $100 \mathrm{ml}$ of culture corresponding to about 25 to $50 \mathrm{mg}$ of total cellular protein are sufficient.

Selective labeling. Chloramphenicol. A selective labeling of cellular proteins can be performed after inhibiting mitochondrial protein synthesis by chloramphenicol. A 5-min preincubation with $4 \mathrm{mg}$ chloramphenicol per ml of culture medium results in an 80 to $90 \%$ inhibition of the labeling of mitochondrially synthesized protein (Sebald et al., 1972), (Jackl and Sebald, 1975). The cytoplasmically made polypeptides, on the other hand, become pulse-labeled by adding low amounts of radioactive leucine, since the main synthesis chain of cellular protein is not affected by the chloramphenicol. This is particularly true for short-term experiments. After longer periods of chloramphenicol preincubation ( $1 \mathrm{hr}$ and longer), cell growth becomes limited by the residual mitochondrial protein synthesis. Consequently, the differences in the extent of labeling of mitochondrial and cytoplasmic translation products diminish.

Two different labeling procedures are used:

1. $\left[{ }^{3} \mathrm{H}\right]$ leucine is incorporated for $30 \mathrm{~min}$ in the presence of chloramphenicol.

2. Same as 1, but the chloramphenicol is removed after the 30 -min labeling period, and the cells are grown for another 1 to $2 \mathrm{hr}$ in the absence of the inhibitor.

In contrast to procedure 1 , procedure 2 allows a definite integration of accumulated labeled polypeptides into newly formed enzyme complexes, because normal cell growth is restored after the removal of the inhibitor. The labeling of mitochondrial translation products remains inhibited under these conditions (Sebald, 1977).

Cycloheximide. A 2-min preincubation of Neurospora crassa cells with $0.1 \mathrm{mg}$ of cycloheximide per $\mathrm{ml}$ of culture medium results in a more than $99 \%$ inhibition of cytoplasmic protein synthesis (Sebald et al., 1973; Sebald et al., 1969). In the presence of cycloheximide the cellular amino acid pools increase fourfold to tenfold, since the main pathway of cellular protein synthesis is blocked. Only a minor percentage of the added radioactive leucine is used up for mitochondrial protein synthesis. Labeling of proteins in the presence of cycloheximide ceases after 20 to $30 \mathrm{~min}$ (Sebald et al., 1969). Consequently, the cells are harvested 30 to 40 min after poisoning. 
Adding $\left[{ }^{3} \mathrm{H}\right]$ leucine (high specific radioactivity, 40 to $60 \mathrm{Ci} / \mathrm{mmole}$ ) in amounts of $1 \mathrm{mCi}$ per $\mathrm{g}$ of total cellular protein results in a labeling of whole mitochondrial protein of 1 to $2 \times 10^{5} \mathrm{dpm} / \mathrm{mg}$. The cycloheximide-resistant labeling can be increased to about $50 \%$ after a transitory incubation of the cells with chloramphenicol. Stimulation is maximal after a 15 - to 30 -min preincubation. A pulse-labeling in the presence of cycloheximide is obtained if the radioactive leucine is chased with cold leucine ( 2 to $5 \mathrm{mM}$ ) after 2 min (Jackl and Sebald, 1975). The labeling in a pulse-chase experiment is 5 to $10 \%$ of the labeling obtained without chase.

Continuous labeling. A continuous labeling of all cellular proteins, that is, precursors and mature proteins, is obtained when the radioactive amino acid is applied in high amounts (Werner, 1974). About 300 $\mu$ mole of leucine are required for the synthesis of $500 \mathrm{mg}$ of cellular protein. Particularly useful is the application of a leucine auxotrophic strain (see Section III.4), since no dilution by endogenous leucine occurs here.

Provided that the radioactive leucine is added to the culture either together with the inoculum or in an early growth phase when the cell mass is still small, precursors and mature proteins should exhibit the same specific radioactivity during the entire growth period of the cells. This type of labeling allows the direct evaluation of protein synthesis rates as well as the amount of precursors present in the cell (Werner, 1974; Werner et al., 1974).

Mass labeling with $\left[{ }^{35} \mathrm{~S}\right]$ sulfate. An inexpensive method for labeling proteins is to cultivate cells in the presence of $\left.{ }^{35} \mathrm{~S}\right]$ sulfate (Hallermayer et al., 1977), (Korb and Neupert, 1978), (Maccecchini, et al., 1979), which is converted metabolically into cysteine and methionine.

Neurospora crassa has been grown in a low sulfate medium (Vogel's minimal medium containing $0.08 \mathrm{mM}$ sulfate, plus $250 \mu \mathrm{Ci} / \mathrm{l}$ sodium $\left[{ }^{35} \mathrm{~S}\right]$ sulfate - specific radioactivity 10 to $1000 \mathrm{Ci} / \mathrm{mole}$ ) for 10 to $12 \mathrm{hr}$. The radioactive sulfate was chased by adding unlabeled magnesium sulfate (final concentration $1 \mathrm{~m} M$ ) and the culture was allowed to grow for a further 1 to $2 \mathrm{hr}$. Under these conditions about $25 \%$ of the added ${ }^{35} \mathrm{~S}$-radioactivity is incorporated into the protein.

\section{The Antibody}

A. PRODUCTION AND PREPARATION OF ANTISERUMS

a. General. Most membrane proteins are exposed to various detergents during the isolation procedure. This treatment may cause more 
or less pronounced conformational changes of the proteins depending on the individual detergent, its concentration, and on numerous other parameters. Often clearly denaturing conditions are applied, for example, dodecylsulfate treatment or extraction with organic solvents. Nevertheless, experience shows that upon immunization with these antigen preparations, precipitating antibodies are obtained in most cases, which are able to recognize specifically the "native" protein components of the membrane.

On the other hand, it may be hazardous to give general guidelines for the practice of immunization with mitochondrial antigens based on random observations. Thus, we restrict our suggestions to selected procedures successfully applied in our laboratories.

For immunization, we use predominantly rabbits, since they are suitable animals for obtaining precipitating serums of high titers and since reasonable amounts of blood can be collected. Healthy bastards weighing about 4 to $5 \mathrm{~kg}$ are obtained from animal breeders and kept for at least 3 weeks before injection. It is recommended that groups of about 2 to 4 animals (depending on the amount of antigen available) be immunized simultaneously to select those antiserums with the desired characteristics. Also control serums should be collected before the treatment is started.

b. Preparation of Immunogens. Prior to the injection of the immunogen, the material is either adsorbed to particles like alumina and bentonite or it is incorporated in water-oil dispersions. For the latter purpose, Freund's adjuvant (incomplete or complete) is frequently used. The emulgation of protein solutions and adjuvant oil is most easily achieved by subjecting the mixture to shearing stresses. For that purpose, the membrane protein is first dissolved in buffer containing detergents, if necessary, and about one or two volumes of Freund's adjuvant are added. The mixture is then drawn into a syringe and expelled through a narrow injection needle under high pressure. The procedure may need to be repeated several times to obtain a stable emulsion of creamy consistency.

c. Injection of Animals. In this section, approved immunization plans for injecting various mitochondrial proteins are offered. Principally, a single dose is injected into multiple (four to six) sites of the animal.

Treatment of Rabbits with Neurospora crassa Proteins. Plan for Injecting Cytochrome Oxidase or ATPase. The protein $(0.5 \mathrm{mg})$ is dissolved in buffered saline and emulsified with an equal volume of incomplete Freund's adjuvant (Behringwerke AG, Marburg, FRG). The mixture is 
injected into the animals four footpads. The procedure is repeated five times at weekly intervals.

Plans for Injecting Polypeptide Subunits of Cytochrome Oxidase or ATPase. The final subunit preparations usually contain a relatively high amount of dodecylsulfate owing to the isolation procedure in the presence of this detergent, followed by a concentration of the polypeptide. The bulk of the detergent must be removed first by dialysis. Preparations ( 1 to $2 \mathrm{ml}$ ) containing up to $0.5 \%$ dodecylsulfate can be injected intramuscularly or subcutaneously without further removal of the detergent.

Immunization with High Individual Doses. Three-quarters to $1 \mathrm{mg}$ of a polypeptide subunit dissolved in $0.5 \mathrm{ml}$ of buffer, containing about $0.5 \%$ of dodecylsulfate, is blended with incomplete Freund's adjuvant. The emulsion is injected deep intramuscularly. Booster injections with the same amount of immunogen are given at biweekly intervals three to five times.

Immunization with Low Individual Doses. One tenth $\mathrm{mg}$ of the polypeptide subunit is emulsified with complete (containing mycobacteria) Freund's adjuvant. The mixture is injected subcutaneously into the back of the rabbit. A battery of 8 to 15 similar injections is applied at intervals of 12 days.

Treatment of Sheep with Rabbit Immunoglobulin. To produce an antirabbit serum for double immunoprecipitation assays, adult sheep are injected intramuscularly with 120 to $200 \mathrm{mg}$ of immunoglobulin isolated from rabbit serum by DEAE-cellulose chromatography (see below). The protein is mixed with incomplete Freund's adjuvant before injection and the treatment is repeated seven times at weekly intervals. If the obtained titer is low, an additional booster injection applied intravenously (30 $\mathrm{mg} \gamma$-globulin in physiological saline) may be required.

d. Collecting Blood. Test bleedings are made during the immunization process, usually 5 days after the restimulating injection. Small amounts of blood are easily obtained from the marginal ear vein of the rabbits. Even larger amounts of blood (120 to $170 \mathrm{ml}$, equivalent to about one-third of the total blood volume of the rabbit) can be withdrawn from the ear vein with some patience. This technique has the advantage that the animal is scarcely injured, it recovers rapidly, and the procedure may be repeated several times at 4-week intervals. If a large amount of blood is desired immediately, bleeding by cardiac puncture is the most suitable method. Up to 200 to $250 \mathrm{ml}$ are obtained from a rabbit weighing 4 to $5 \mathrm{~kg}$. 
From sheep, small samples of blood can also be taken from the marginal ear vein. Terminal bleeding ( 1 to $2 l$ ) is made through the external jugular vein.

Whenever collecting blood, caution is required to avoid hemolysis. Food should be withheld from the animals the evening before to reduce serum lipids if the blood is intended for storage.

e. Separation of Serum. To obtain rapid clotting, the withdrawn blood is commonly collected in glass tubes or glass beakers. The blood is allowed to stand at room temperature for 1 to $2 \mathrm{hr}$. It is then transferred to a refrigerated storage place for about $3 \mathrm{hr}$. Any clots that have not retracted from the walls are loosened gently with a glass rod. The serum is then carefully decanted. The cruor is stored overnight in the cold and the residual serum is collected by low speed centrifugation.

The serum is stored at $-20^{\circ} \mathrm{C}$ or preferably at $-70^{\circ} \mathrm{C}$, after being dispensed in 1 to $2 \mathrm{ml}$ amounts to avoid repeated freezing and thawing during sampling.

\section{B. PURIFICATION OF THE ANTIBODY}

For many immunological approaches involving membrane proteins, the unfractionated serum may be used. However, a partial or even total removal of serum components, other than the immunoglobulin, becomes necessary if side effects (e.g., unspecific adsorption, lability of serum components in the presence of detergents, cleavage of antigenic material by serum proteases) occur, which interfere quantitatively or qualitatively with the antigen-antibody reaction. Also unfavorable dilution of the reaction partners by application of serums of low titer may lead to difficulties when collecting the specific antigen. In the following section we describe briefly three standard techniques which permit purification of the antibody to widely different extents. Whereas the first technique results only in a partial removal of non- $\gamma$-globulin serum proteins, a highly purified immunoglobulin fraction is obtained by the second approach. The third technique allows the isolation of monospecific immunoglobulins. All three techniques are applicable to rabbit and sheep serum.

We have chosen these procedures because of their simplicity. For additional information on the numerous other separation techniques the reader is referred to the standard immunological literature.

a. Serum Fractionation with Ammonium Sulfate. The serum is diluted with an equal volume of buffer A $(10 \mathrm{~m} M$ sodium phosphate buffer, $15 \mathrm{mM} \mathrm{NaCl}, \mathrm{pH} 7.4$ ) to which saturated ammonium sulfate is added to reach $40 \%$ saturation. Twenty minutes later the precipitate is 
collected by centrifugation and the supernatant is discarded. The precipitate is dissolved in buffer A (twice the volume of the original serum) and ammonium sulfate is added to make the solution 33\% saturated. After centrifugation the heavy precipitate is resolved in buffer $\mathrm{A}$ and dialyzed against $10 \mathrm{~m} M$ phosphate buffer, $\mathrm{pH} 8.0$. The sample is centrifuged again and the supernatant is concentrated to a solution containing 30 to $40 \mathrm{mg} / \mathrm{ml}$ by ultrafiltration. The crude $\gamma$-globulin fraction obtained by this procedure consists of about 60 to $70 \%$ immunoglobulin $\mathrm{G}$ (IgG). The residual portion of other serum proteins precipitated consists mainly of albumin.

b. DEAE-Cellulose Chromatography. The purification of immunoglobulin by DEAE-cellulose chromatography is carried out according to the methods of Sober and Peterson (Sober et al., 1956; Peterson and Sober, 1956). Although whole serum (following dialysis against starting buffer) may be applied to this anion exchanger, it is recommended that the column be loaded with a crude preparation of $\gamma$-globulins as obtained by the salt fractionation procedure explained above. This technique not only allows for chromatography on a small scale, but also more concentrated and rarely contaminated immunoglobulin preparations are obtained.

A column is filled with DEAE-cellulose (preferably with "preaged" cellulose material) and it is equilibrated with $10 \mathrm{~m} M$ sodium phosphate buffer, $\mathrm{pH}$ 8.0. The salt-precipitated (and dialyzed) $\gamma$-globulin fraction is loaded onto the column. The amount depends on the capacity of the DEAE-cellulose. As a rule of thumb, about $500 \mathrm{mg}$ of crude $\gamma$-globulin fraction may be applied per $35 \mathrm{ml}$ bedvolume of cellulose with a capacity of 0.7 to $0.9 \mathrm{meq} / \mathrm{g}$. The immunoglobulin $\mathrm{G}$ is eluted rapidly by phosphate buffer with low ion strength $(10 \mathrm{mM})$. This fraction is usually free of other serum proteins. The recovery of IgG is in the range of 70 to $80 \%$. The residual serum protein is removed from the column by washing with $0.5 \mathrm{M} \mathrm{NaCl}$.

c. Isolation of Monospecific Antibodies. If a sufficient amount of antigen is available ( 1 to $2 \mathrm{mg}$ ) it is comparatively easy to isolate monospecific antibodies from the antiserum. The application of monospecific antibodies offers certain advantages:

1. The reactivity of the antibody preparation is greatly increased compared to that of a low titer antiserum.

2. Other serum proteins, including proteases, are efficiently removed.

3. The amount of protein A/Sepharose or anti-antiserum applied during double immunoprecipitation experiments is very much reduced. This also diminishes unspecific absorption to other proteins. 
4. Finally, the monospecific antibodies can be purified under conditions later applied during the immunoprecipitation experiments, that is, in the presence of detergents.

As an example, the purification of $\gamma$-globulins directed against the ATPase proteolipid (dicyclohexyl-carbodiimide-binding protein) from Neurospora crassa (Sebald et al., 1979; Michel et al., 1979) is given in detail.

Preparation of the Affinity $\mathrm{Gel}$. A preparation of proteolipid is dissolved $(2 \mathrm{mg} / \mathrm{ml})$ in chloroform/methanol $(2 / 1, \mathrm{v} / \mathrm{v})$. Three $\mathrm{ml}$ of Affi-Gel 10 (Bio-Rad Laboratories) are washed twice on fritted glass with $5 \mathrm{ml}$ of chloroform/methanol (2/1). One $\mathrm{g}$ (wet weight) of the Affi-Gel is mixed to $1 \mathrm{ml}$ of the proteolipid solution. Then $20 \mu \mathrm{l}$ of $1 M$ MOPS buffer, adjusted with $\mathrm{NaOH}$ to $\mathrm{pH} 7.4$, are added to the mixture. After incubation for $4 \mathrm{hr}$ at room temperature, excess of active esters is eliminated by adding $50 \mu \mathrm{l}$ of $1 M$ TRAP-HCl, $\mathrm{pH} \mathrm{8.0,}$ and the suspension is incubated for another $4 \mathrm{hr}$. The gel is washed again on fritted glass, first with $10 \mathrm{ml}$ of chloroform/methanol (2/1), then with $10 \mathrm{ml}$ of methanol, $10 \mathrm{ml}$ of $\mathrm{H}_{2} \mathrm{O}, 10 \mathrm{ml}$ of $0.1 \mathrm{M}$ sodium phosphate plus $1 \%$ dodecylsulfate, $\mathrm{pH} 8.0$, and finally with $5 \mathrm{ml}$ of $0.1 M$ sodium phosphate, $\mathrm{pH}$ 8.0. The gel is stored in the refrigerator in phosphate buffer plus $0.05 \%$ sodium azide (as a preservative). The affinity gel contains about $1 \mathrm{mg}$ of bound proteolipid per gram (wet weight), as determined using a proteolipid preparation labeled uniformly with $\left[{ }^{3} \mathrm{H}\right]$ leucine.

Affinity Chromatography. A crude $\gamma$-globulin fraction isolated from a rabbit antiserum against proteolipid (ammonium sulfate precipitation, see Section II.2.B.a.) is used as starting material. A column $(15 \mathrm{~cm} \times 1$ $\mathrm{cm})$ is filled with the proteolipid Affi-Gel ( $1 \mathrm{~g}$ wet weight) and equili-

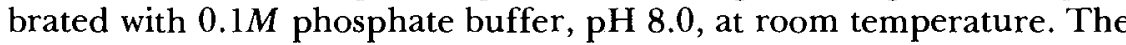
solution of the crude $\gamma$-globulins $(60 \mathrm{mg} / \mathrm{ml})$ is applied to the gel in five $1-\mathrm{ml}$ portions. Each portion is allowed to sit in the gel for $5 \mathrm{~min}$. The gel is washed twice with $5 \mathrm{ml}$ of phosphate buffer $(0.1 \mathrm{M}, \mathrm{pH} 8.0)$ followed by $3 \mathrm{ml}$ of water. The bound $\gamma$-globulin is eluted from the column with $3 \mathrm{ml}$ of $3 \%$ acetic acid. The eluate is cooled immediately to $0^{\circ} \mathrm{C}$ and adjusted to $\mathrm{pH} 7$ with $2 M$ Tris base. The protein is precipitated with ammonium sulfate ( $50 \%$ saturation), sedimented by a 10 -min centrifugation at $12,000 \times \mathrm{g}$, and then dissolved in $1 \mathrm{ml}$ of $10 \mathrm{mM}$ phosphate buffer, $\mathrm{pH}$ 8.0.

Experience has shown that $300 \mathrm{mg}$ of a particular crude $\gamma$-globulin fraction yields about $10 \mathrm{mg}$ of monospecific antibodies. When analyzed by an Ouchterlony double-diffusion test, the monospecific antibodies exhibit an increased reaction in contrast to the faint precipitates ob- 
tained with the crude $\gamma$-globulin fraction. On the other hand, the protein portion not bound to the affinity gel showed no detectable reaction against the proteolipid.

A similar protocol is used for the isolation of monospecific antibodies against subunits of the $F_{1}$-ATPase from Neurospora crassa. These polypeptides are coupled to Affi-Gel 10 in $0.1 \mathrm{M}$ phosphate buffer containing $1 \%$ dodecylsulfate at $\mathrm{pH} \mathrm{8.0.} \mathrm{The} \mathrm{affinity} \mathrm{gels} \mathrm{can} \mathrm{be} \mathrm{used}$ repeatedly. They are regenerated by subsequent washings with water, with $0.1 M$ phosphate buffer- $1 \%$ dodecylsulfate, and finally with phosphate buffer alone.

\section{The Antibody-Antigen Reaction}

A number of immunological methods have been used for the investigation of mitochondrial membrane proteins. Naturally, the underlying principles of these methods do not differ from the "classical" techniques. In practice, however, most of these procedures have had to be modified and adapted to meet special requirements. Many problems arise from the application of detergents. Some membrane proteins, when released from their membrane environment, tend to aggregate or to cause irreversible precipitation, or they may be adsorbed unspecifically to other components. In addition, various detergents drastically influence the antibody-antigen reaction at certain concentrations. In this section we will try to outline some of the analytical methods which we deem relevant for biogenetic studies. Special emphasis is put on the experimental limitations of the techniques and on the interpretation of the results.

\section{A. SOLUBILIZATION OF MITOCHONDRIAL MEMBRANE PROTEINS}

Mitochondrial membranes may be solubilized with a variety of detergents (Helenius and Simons, 1975). A suitable detergent for immunochemical studies, however, must meet a dual requirement: (1) The detergent should solubilize the membrane protein thoroughly, and (2) the detergent should not interfere with the immunoreaction at the same time. These prerequisites narrow the number of applicable agents.

Extracts of whole mitochondrial proteins are best achieved by treating mitochondrial suspensions either with bile acids (preferably desoxycholate) or with nonionic surfactants of the polyoxyethyleneglycol group. From our experience, the most useful detergent of the latter category proved to be Triton X-100. 
Procedure. All steps are performed at $4^{\circ} \mathrm{C}$. Mitochondria are suspended in $0.1 \mathrm{M}$ phosphate buffer, $\mathrm{pH} 8.0$, or in $0.01 \mathrm{M}$ Tris- $\mathrm{HCl}, 0.3 \mathrm{M}$ $\mathrm{KCl}$ (final protein concentration 1 to $2 \mathrm{mg} / \mathrm{ml}$ ) and Triton $\mathrm{X}-100$ is added from a $20 \%$ stock solution in water to give a final detergent concentration of $1 \%$. The Triton concentration may be varied (depending on the amount of mitochondrial protein) between 0.5 and $3 \%$ without interfering with the subsequent immunoprecipitation. The lysate is centrifuged for $20 \mathrm{~min}$ at $50,000 \times \mathrm{g}$. Ninety-five percent of the total mitochondrial protein is found in the supernatant (Werner 1974) if the procedure was performed with freshly prepared mitochondria. For mitochondrial suspensions which have been frozen and thawed repeatedly prior to the addition of Triton X-100, the solubilization rate may drop to $70 \%$.

A special comment needs to be made for the application of dodecylsulfate. Because of its strong dissociation effect on protein complexes, this detergent is widely applied for the isolation of individual membrane polypeptides. After dodecylsulfate treatment, however, most polypeptides are no longer soluble solely in mild detergents, such as Triton X-100. On the other hand, the presence of dodecylsulfate interferes drastically with the antigen-antibody reaction. Although immunocomplexes may be formed at dodecylsulfate concentrations below $0.05 \%$, the reaction is far from quantitative. Nevertheless, qualitative reactions in agar gels (immunodiffusion or crossed immunoelectrophoresis) may easily be performed in the presence of dodecylsulfate. The prerequisites for a successful approach are the rapid dilution of the actual dodecylsulfate concentration and the partial replacement of this detergent by Triton X-100 to avoid precipitation artifacts. Similarly to the use of agar gels, membrane proteins can be precipitated from aqueous solutions containing mixed dodecylsulfate-Triton micelles. The actual proportion of the two detergent concentrations tolerated by the antibody reaction must be determined individually for each system. As a rule of thumb, in direct precipitation assays the absolute dodecylsulfate concentration should not exceed $0.1 \%$ and a Triton concentration of at least $2 \%$ is favorable.

\section{B. PRECIPITATION REACTION IN GELS}

a. Double Immunodiffusion. The simplest technique for the detection of an antibody-antigen reaction is certainly the double diffusion on slides according to Ouchterlony (Ouchterlony, 1958). As in other precipitation tests, the double-diffusion test depends on the specific precipitation of the antigen-antibody complexes at the proper ratios 
and on the solubility of the precipitates in excess of antigen or antibody. The position of the precipitation line is determined by the relative diffusion rates of antigen and antibody and their relative concentrations.

The presence of Triton X-100 on the agar diminishes precipitation artifacts and allows the application of antigens dissolved in dodecylsulfate. The tolerated amount of dodecylsulfate applied to an individual well depends not only on the Triton X-100 concentration in the agar, but largely on the diffusion distance between the reaction partners. Precipitation artifacts are often caused by wells too close together.

The identification of precipitation lines is usually easy if a pure antigen preparation is available. Complex mixtures of antigens, such as whole membrane extracts, are more difficult to interpret, particularly if a number of superimposed precipitation lines are produced. In this context, the proteolytic activity of crude mitochondrial extracts should be kept in mind. Moreover, the appearance of a single band does not automatically indicate chemical or immunological purity. Only antigens that diffuse freely through the gel can be assumed to form proper lines of precipitation. This is an important point for the interpretation of precipitation patterns, since different mitochondrial membrane proteins may need different concentrations of detergents for their diffusion.

Procedure. Agar of high purity (e.g., agar purum, Behringwerke, Marburg, FRG) is dissolved in $0.05 M$ sodium barbital buffer, $\mathrm{pH} 8.3$, to arrive at a $1 \%$ solution. The mixture is then autoclaved. After remelting the agar solution and cooling it to $60^{\circ} \mathrm{C}$, preservations such as merthiolate $(1: 10,000)$, or antibiotics (streptomycin and penicillin) may be added. The agar is stored in test tubes (5-ml portions) at $4^{\circ} \mathrm{C}$. In order to prepare slides for double-diffusion tests, the agar in the tubes is heated to 60 to $70^{\circ} \mathrm{C}$ in a water bath. Triton X-100 (from a $20 \%$ stock solution in water) is added to the liquid agar to yield a detergent concentration of $1 \%$. After the addition of Triton the mixture turns into a "milky" solution. It is immediately poured ( $2.3 \mathrm{ml}$ per slide) on clean microscope slides $(76 \times 26 \mathrm{~mm})$. After the agar solidifies only a slightly opalescent layer of about $2 \mathrm{~mm}$ thickness has formed. Cylindrical wells (3 or $6 \mathrm{~mm}$ in diameter, 5 to $7 \mathrm{~mm}$ apart) are cut by means of an appropriate template. The agar plugs are suctioned off by a pipette tip connected to a vacuum line. The small wells hold 5 to $7 \mu \mathrm{l}$, the larger ones 25 to $30 \mu \mathrm{l}$. Test solutions are pipetted into the wells and the agar plates are placed strictly horizontally in a moist chamber. The slides need 12 to $15 \mathrm{hr}$ to develop at room temperature, or 36 to $48 \mathrm{hr}$ at $4^{\circ} \mathrm{C}$. Faint precipitation lines are made visual by staining with 
coomassie brillant blue. For that purpose, the agar slides are first soaked in a $0.15 \mathrm{M}$ saline solution containing $0.1 \%$ Triton for $48 \mathrm{hr}$ to remove all soluble proteins.

One of the main advantages of the double-diffusion test is that it allows a rapid qualitative characterization of the antigen and antibody, respectively. Only minor amounts of the test substances are required because of the high sensibility of the assay. Some examples of the applicability and the interpretation of the diffusion test involving mitochondrial antigens are detailed in the following experiments.

The aim of the assays was to characterize two antibody preparations obtained from rabbits: immunoglobulin to cytochrome oxidase from Neurospora crassa and immunoglobulin to the isolated subunit 3 of the same enzyme (Werner, 1974). The reactions of the antibodies to the purified membrane components and to whole mitochondrial membrane extracts were examined. A single precipitin line between cytochrome oxidase and immunoglobulin against holoenzyme was obtained (Figure 1A). An identical line was formed with solubilized mitochondrial membranes as antigen. However, this antibody did not react with a preparation of subunit 3 of the oxidase. Also, no reaction was observed between cytochrome oxidase and $\gamma$-globulin of untreated animals.
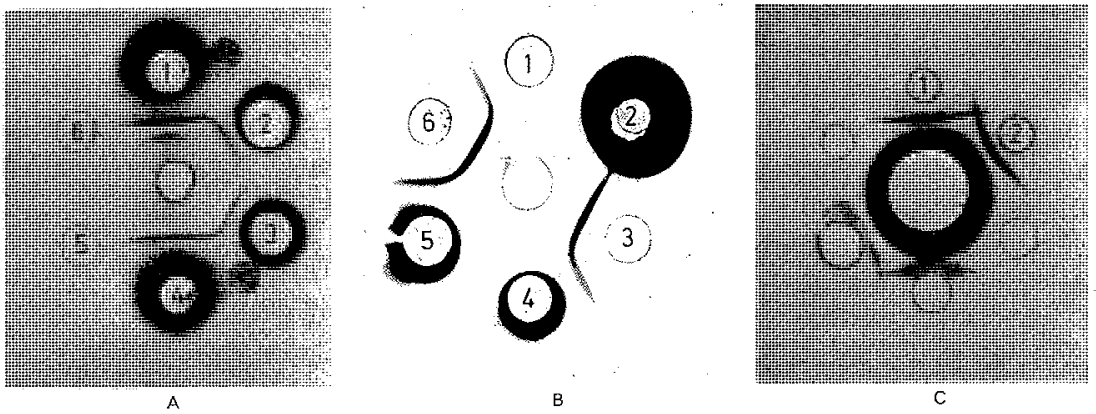

Figure 1. Double diffusion in agar containing $1 \%$ Triton $\mathrm{X}-100$. All plates were stained with coomassie brillant blue. (A) Center well: anticytochrome oxidase $\gamma$-globulin (10 $\mathrm{mg} / \mathrm{ml})$; wells 1 and 4: cytochrome oxidase $(4 \mathrm{mg} / \mathrm{ml})$; wells 2 and 3: Triton $\mathrm{X}-100$ solubilized mitochondrial membranes $(0.5$ and $1.5 \mathrm{mg} / \mathrm{ml}$, respectively); well 5 : subunit 3 $(3 \mathrm{mg} / \mathrm{ml})$; well 6: $\gamma$-globulin of untreated animals $(10 \mathrm{mg} / \mathrm{ml})$. (B) Center well: subunit 3 $(1 \mathrm{mg} / \mathrm{ml}$ ); well 1 : antisubunit $3 \gamma$-globulin absorbed with subunit 3 ; well 2: subunit 3 absorbed with subunit-specific $\gamma$-globulin; well 3 and 6 : antisubunit $3 \gamma$-globulin (2 $\mathrm{mg} / \mathrm{ml}$ ); well 4: antisubunit $3 \gamma$-globulin absorbed with Triton X-100-solubilized mitochondrial membranes; well 5: Triton X-100-solubilized mitochondrial membranes (5 $\mathrm{mg} / \mathrm{ml})$. (C) Center well: Triton X-100-solubilized mitochondrial membranes $(4 \mathrm{mg} / \mathrm{ml})$; well 1: anticytochrome oxidase $\gamma$-globulin $(3 \mathrm{mg} / \mathrm{ml})$; well 2 : antisubunit $3 \gamma$-globulin (8 $\mathrm{mg} / \mathrm{ml}$ ) (Werner, 1974). 
In another set of experiments the immunoglobulin preparation directed against the isolated enzyme subunit 3 was tested. In the Ouchterlony analysis (immunoglobulin against subunit) a single sharp precipitation line was observed. This antibody did not react with other subunits of cytochrome oxidase (not shown). Furthermore, it did not precipitate a preparation of holocytochrome oxidase. However, cytochrome oxidase, which was previously dissociated with dodecylsulfate, reacted with the subunit-specific antibody on agar gels. The pattern was identical to that which was obtained with the isolated subunit. Figure 1B shows a double-diffusion test with Triton X-100 solubilized mitochondrial membranes as antigen. A single line of precipitation was observed between membranes (well 5) and antisubunit 3 immunoglobulin (well 6 ). This precipitin line is identical to that obtained with a preparation of subunit 3 (center well). In well 1 of the gel, subunit-specific immunoglobulin was absorbed with subunit 3 . The absorbed globulin no longer reacted with subunit 3 (center well). Subunit 3 was present in excess in well 1 as indicated by the weak precipitin line appearing between the observed immunoglobulin (well 1) and the immunoglobulin in well 6. A similar experiment was carried out with mitochondrial membranes as an adsorbant (well 4). No precipitation could be detected against the center well. Furthermore in well 2, subunit 3 was successfully absorbed by specific immunoglobulin.

The fact that the antibody to holocytochrome oxidase and the antibody to subunit 3 recognizes different antigens in mitochondrial membranes, is revealed by the diffusion test shown in Figure 1C. The crossing over of the two precipitin lines demonstrates that components with different antigenic determinants are involved.

b. Immune Replica Technique. The application of this technique to mitochondrial membrane proteins has been recently described (Cabral et al., 1978). Radioactively labeled mitochondrial proteins from yeast are first subjected to dodecylsulfate gel electrophoresis on polyacrylamide gels. The slab is then soaked briefly in water and placed onto an agarose layer containing antiserum to yeast cytochrome oxidase subunit 2. The sandwich is incubated for 16 to $18 \mathrm{hr}$ in a humid chamber. Then the electrophoresis gel and the agarose layer are separated, washed, and dried. The immunoprecipitated protein in the agarose is made visible by staining with coomassie blue or by radioautography. The antigen involved is identified on the electrophoresis gel by comparing the autoradiogram of the dried gel with the autoradiogram of the immune replica. 
c. Crossed Immunoelectrophoresis. The two-dimensional crossed immunoelectrophoresis according to Converse and Papermaster (1975) offers a very elegant procedure for the characterization of membrane polypeptides and the applied antibody preparations, respectively. In their method the membrane antigens are first separated electrophoretically on polyacrylamide gels in the presence of dodecylsulfate. Afterwards, the proteins are electrophoresed in the second dimension through an agarose layer containing the detergent Lubrol, in order to "bind" the excess of dodecylsulfate, and are then drawn into an agarose layer containing antiserum, where the immune reaction takes place. Precipitin arcs are formed at a position corresponding to the polypeptide position in the first dimension. The original procedure, however, is beset with several shortcomings (Chua and Blomberg, 1979): (1) Many membrane polypeptides fail to migrate completely out of the first dimension. (2) Non-specific precipitation of serum proteins by dodecylsulfate occurs in the region just above the Lubrol-containing intermediate gel. These artifacts are deleted by the incorporation of an additional agarose gel strip containing an anionic detergent (e.g., desoxycholate) on the cathodal side of the dodecylsulfate gel slab (Chua and Blomberg, 1979). We believe that the crossed immunoelectrophoresis, which has been considerably improved by this modification, may also be advantageous in working with mitochondrial membranes. In contrast to the double immunodiffusion, this procedure allows the precise identification of individual antigens in the immunoprecipitate.

d. Other Techniques. Whereas the double immunodiffusion and the immune replica technique are qualitative methods, the crossed immunoelectrophoresis offers the possibility for quantification. Much simpler devices for quantitative determinations are supplied by the single radial immunodiffusion (Mancini et al., 1965), and the rocket immunoelectrophoresis (Laurell, 1972). In the first procedure, the area of the developed diffusion ring is a function of the amount of antigen applied at a given antibody concentration in the gel, or vice versa.

The same principle is also followed by rocket electrophoresis. In this case the antigen is electrophoresed into the antibody-containing gel, allowing a much quicker analysis. The height of the rocket-shaped precipitate correlates to the amount of antigen applied. A proper quantification of mitochondrial membrane antigens, however, is somewhat troublesome. These techniques are restricted to membrane antigens mobile in detergents which definitely do not interfere with the 
immunoreaction (only charged detergents may be used for the rocket electrophoresis). The application of dodecylsulfate, for example, is excluded, since no intermediate layer for the formation of mixed detergent micelles exists (see crossed immunoelectrophoresis).

\section{PRECIPITATION REACTION IN LIQUID MEDIA}

a. Direct Immunoprecipitation. Test tube immunoprecipitation of membrane proteins from whole mitochondrial extracts has proved to be one of the most powerful tools in biogenetic studies. The technique allows a separate and precise analysis of the immunoprecipitate formed and permits quantitative determinations. One disadvantage compared with the agar method is that larger amounts of the reacting components are required. This is partly compensated by the application of radioactively labeled antigens. On the other hand, the rapid isolation of mitochondrial antigens on a large scale becomes feasible. Procedure:

Mitochondria are solubilized according to the procedure given in Section II.3.A. An appropriate amount of rabbit antiserum (usually 0.1 to $0.4 \mathrm{ml}$ ) is added to $1 \mathrm{ml}$ of Triton extract containing 1 to $2 \mathrm{mg}$ of mitochondrial protein and $0.1 M$ phosphate buffer, $\mathrm{pH} \mathrm{8.0.} \mathrm{The} \mathrm{mix-}$ ture is incubated at $4^{\circ} \mathrm{C}$ for at least $6 \mathrm{hr}$ (usually overnight) to achieve complete precipitation. The supplementation of the incubation medium with 0.2 to $0.3 \mathrm{M} \mathrm{KCl}$ accelerates the precipitin reaction. In this case, the precipitate may be collected after $4 \mathrm{hr}$. (The period required for complete precipitation depends both on the applied serum and on the nature of the membrane antigen and, therefore, has to be determined individually.) The sample is centrifuged for $2 \mathrm{~min}$ in an Eppendorf microcentrifuge and the supernatant is carefully removed from the pelleted precipitate. The precipitate is washed twice with $0.1 M$ phosphate buffer, $\mathrm{pH} 8.0$, containing $1 \%$ Triton X-100 $(1 \mathrm{ml}$ each), and then twice with the same buffer without detergent. The washing procedure is made very effective by using a small conical homogenizer pestle, which fits tightly into the microtest tubes. The finely suspended immunoprecipitate is collected each time by a 2-min centrifugation. Each precipitin analysis should include appropriate controls, for instance, preimmune serum plus mitochondrial extracts. All operations are carried out in the cold.

The quantitative course of the precipitin reaction between mitochondrial membranes (from Neurospora crassa) and a rabbit anticytochrome oxidase immunoglobulin is shown in Figure 2. Increasing amounts of ${ }^{14} \mathrm{C}$-labeled, solubilized mitochondrial membranes were 


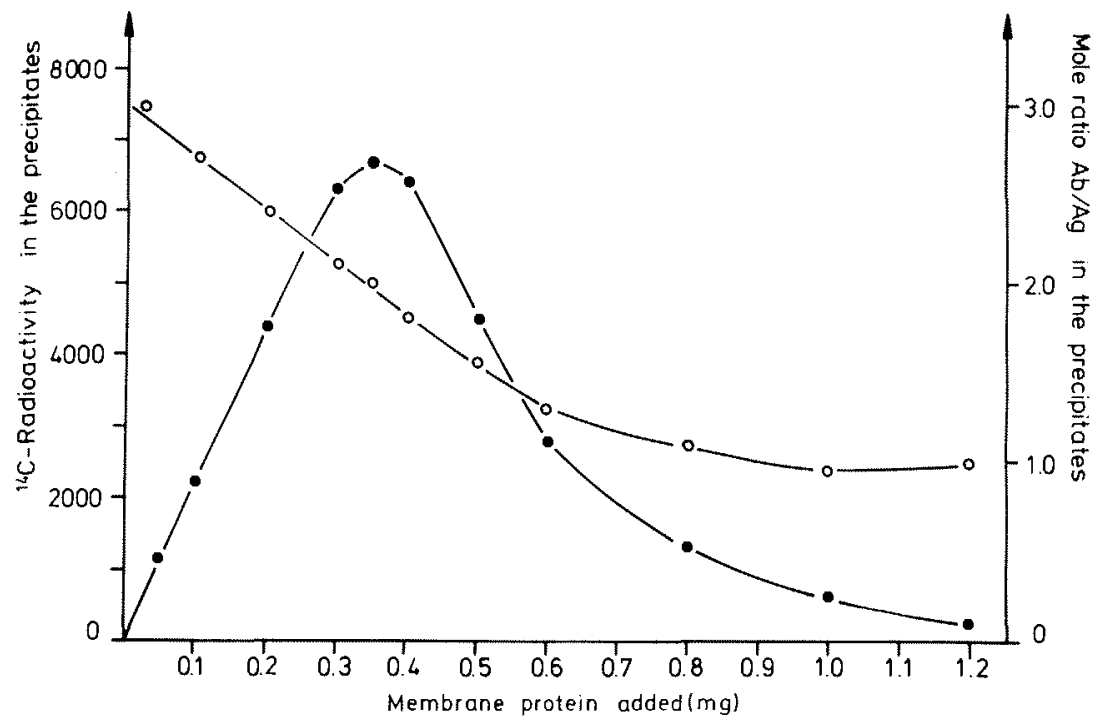

Figure 2. Immunotitration of mitochondrial membranes with antibodies against cytochrome oxidase. Constant amounts $\left(0.6 \mathrm{mg}\right.$ ) of ${ }^{3} \mathrm{H}$-labeled (using $\mathrm{N}$-succinimidyl-[2,3,- $\left.{ }^{3} \mathrm{H}\right]$ propionate) anticytochrome oxidase $\gamma$-globulin (specific activity $381,630 \mathrm{cpm} / \mathrm{mg}$ ) were treated with increasing amounts of solubilized mitochondrial membranes (specific radioactivity $193,620 \mathrm{cpm} / \mathrm{mg}$ ) prepared from Neurospora cells labeled uniformly with $\left[{ }^{14} \mathrm{C}\right]$ leucine. $(\bullet \bullet){ }^{14} \mathrm{C}$ radioactivity in the precipitates, $\mathrm{O}-\mathrm{O}$ mole ratios $\mathrm{Ab} / \mathrm{Ag}$ calculated from the ${ }^{3} \mathrm{H}$ radioactivity and ${ }^{14} \mathrm{C}$ radioactivity found in the precipitates (Werner, unpublished results).

added to constant amounts of ${ }^{3} \mathrm{H}$-labeled immunoglobulin. The ${ }^{14} \mathrm{C}$ radioactivity found in the immunoprecipitates is a measure for the precipitated membrane protein. A typical Heidelberger curve was obtained for the precipitated cytochrome oxidase: increasing amounts in the antibody excess zone, a maximal amount in the equivalence zone, and decreasing amounts in the antigen excess zone. The experiment defined the amount of antigen needed to yield a precipitate at a given concentration of antibodies. Since a ${ }^{3} \mathrm{H}$-labeled immunoglobulin fraction of known specific activity was applied, the mole ratios antibody/ antigen ( $\mathrm{Ab} / \mathrm{Ag}$ ) can be calculated. They are also plotted in Figure 2. A continuous decline in the $\mathrm{Ab} / \mathrm{Ag}$ ratio of the precipitates was obtained. Maximum precipitation in this particular system was observed at an $\mathrm{Ab} / \mathrm{Ag}$ ratio of about 2.7. In the presence of large excess of antigen a critical value of about 1.0 was approached. Beyond that value soluble $\mathrm{Ab} / \mathrm{Ag}$ complexes had formed. On the other hand, the membrane protein precipitated in the equivalent zone may be used for the 
quantitative determination of the cytochrome oxidase content of the mitochondrial membranes (see Section III.1).

b. Double Immunoprecipitation. This technique has proved to be particularly useful for antigen-antibody systems which either do not form an immunoprecipitate as a result of too few antigenic determinants on the antigen, or which do form precipitates, but of an extremely small size. By the reaction of the first antibody, bound to the antigen, with a second antiimmunoglobulin antibody, a sizable lattice is built and a sufficiently bulky precipitate is obtained, which can be collected and analyzed. This technique has been successfully introduced to the mitochondrial field to isolate components such as precursor proteins of cytochrome oxidase, present in the membrane only in minimal amounts (Werner, 1974).

Procedure. About 100 to $150 \mu \mathrm{g}$ of rabbit immunoglobulin (isolated by the DEAE-cellulose procedure, see Section II.2.B.b) directed to a minor membrane component, is added to a mitochondrial extract containing 1 to $2 \mathrm{mg}$ of protein, $2 \%$ Triton $\mathrm{X}-100$, and $0.1 \mathrm{M}$ phosphate buffer, pH 8.0 (see Section II.3.A). The sample is incubated for 2 min, after which an appropriate amount of an immunoglobulin preparation from sheep directed to rabbit $\gamma$-globulin is added. After $12 \mathrm{hr}$ of further incubation the mixture is centrifuged. The precipitates are washed as described in the procedure for direct immunoprecipitation. All operations are carried out at $4^{\circ} \mathrm{C}$.

Principally, the double immune assay may also be carried out with unfractionated serums. Much less contaminated immunoprecipitates are obtained, however, if immunoglobulin preparations are used instead of serums. This is especially true for the antibody to rabbit immunoglobulin. In our laboratories a crude fractionation of the sheep antiserum by ammonium sulfate was found sufficient for most purposes. Between 60 and $76 \%$ of the added rabbit immunoglobulin was precipitated under optimal conditions (compare also panel B of Figure 3 ). Sometimes it may be favorable to expend only a very small amount of the rabbit antibody. In this case the assay system must be supplemented with carrier immunoglobulin from untreated rabbits to get a sizable precipitate with the sheep antibody. This procedure is acceptable as long as the specific antibody is still present in a molar excess to the tested membrane component.

c. Support Fixed Antibodies. This technique makes use of an immunoglobulin attached to a solid phase either by adsorption or by a covalent conjugation. The method has the same application range as the double immunoprecipitation. Technically speaking, the treatment 
with the second (sheep) antibody is replaced by the addition of an immobilized rabbit antibody.

The support fixed immunoglobulin is added in the form of suspensions to the assay solutions and after a short incubation time (some minutes), the bound antigen is separated by centrifugation.

For a covalent linkage of $\gamma$-globulin to a solid phase, generally cellulose, Sepharose or Sephadex is used as the support medium (for detailed information see Ruoslahti, 1976). Coupling is carried out mainly by the cyanogen bromide technique. Although excellent results have been obtained with this procedure, we want to point out some difficulties that may arise. The coupling process, for example, may waste antibody if excellent coupling efficiencies are not obtained. Furthermore, the direct conjugation of the $\gamma$-globulin to the support can lead to an activity loss of the antibody. This may be due to chemical modifications of the protein or to a coupling of part of the $\gamma$-globulin in a way that causes steric hindrance of the antigen-antibody reaction. Nevertheless, this method provides a powerful tool for the specific isolation of antigens, particularly on a large scale.

Recently a novel approach was developed to avoid the difficulties mentioned above. The method involves protein A from Staphylococcus aureus, a bacterial cell wall component which binds specifically to the $\mathrm{F}_{c}$-portion of a wide variety of IgG molecules from several species (Forsgren and Sjöquist, 1966; Kronvall and Williams, 1969). Thus, the bacterial polypeptide is excellently suited for the isolation of immunoglobulin which has previously reacted with the antigen. Both the adsorbant and an "insoluble" support are supplied if formalin-fixed whole Staphylococci bearing protein A are used (e.g., Jonsson and Kronvall, 1974; Welsch et al., 1975; Kessler, 1976; Cullen and Schwartz, 1976; Fan and Mueller-Lantzsch, 1976). To reduce contamination of the precipitate and also to adapt the procedure to an effective microscale we prefer Sepharose as a solid support (Werner and Machleidt, 1978).

Procedure. Protein A is isolated from Staphylococcus aureus strain Cowan I (Hjelm et al., 1972) and the protein is coupled to Sepharose $4 \mathrm{~B}$ by the cyanogen bromide method, as described by Axén et al. (1967). A commercially available protein A/Sepharose preparation (Pharmacia, Uppsala, Sweden) containing $2 \mathrm{mg}$ protein A per $\mathrm{ml}$ swollen gel may be used as well. Mitochondria are suspended in a $0.1 M$ phosphate buffer, $\mathrm{pH} 8.0$ (buffer A), and lysed by the addition of Triton X-100 (final concentration 2\%). After the clarifying spin (see Section II.3.A) the Triton extract (usually 0.8 to $1.2 \mathrm{ml}$ ) is treated either with $30 \mu 1$ of whole rabbit antiserum to a protein component 
present in minor amounts in mitochondria, or with 110 to $220 \mu \mathrm{g}$ of IgG prepared from that serum. After $5 \mathrm{~min}$ of incubation, protein A/Sepharose gel (about $40 \mu \mathrm{l}$ of packed gel suspended in 3 volumes of buffer) is added and the sample is shaken gently for $15 \mathrm{~min}$. The gel is collected by centrifugation and washed three times with buffer A containing $2 \%$ Triton, and then washed twice with buffer A. All operations are carried out at 0 to $4^{\circ} \mathrm{C}$.

A comparison between the protein A/Sepharose technique and the double-immunoprecipitation method described in the preceding section is shown in Figure 3. The effectiveness for precipitating rabbit IgG in the presence of $2 \%$ Triton was tested by means of radioactively labeled immunoglobulin. The radioactivity remaining in the supernatants of the samples after centrifugation indicates that a maximum of $96 \%$ of the applied IgG could be entrapped by the protein $\mathrm{A} / \mathrm{Sepharose}$ gel (Figure 3A). In the case of the double immunoprecipitation involving antirabbit IgG from sheep, a maximum of $76 \%$ of labeled rabbit immunoglobulin could be removed from the solution (Figure 3B).

The advantages of the solid-phase antibody systems-especially the protein A/Sepharose technique-over the double immunoprecipitation may be summarized briefly as follows: Quantitative precipitation reactions, increased sensitivity, rapidity (minutes versus hours), and versatility. For instance, sequential titrations of membrane proteins, by addition of immunoglobulins of different specificity to an individual extract, become feasible. Furthermore, the technique is suitable for the isolation of membrane antigens on a large scale (Werner and Machleidt, 1978). To avoid contamination of the isolated antigen preparations with immunoglobulin, the antibodies may be covalently coupled to protein A previously linked to the Sepharose support (Werner and Machleidt, 1978).

d. Analysis of the Antibody-Antigen Complex. The washed immunoprecipitates containing the isolated membrane components are analyzed by polyacrylamide electrophoresis in the presence of dodecylsulfate. Before the material is subjected to the electrophoresis, the antigens are unlinked from the immunoglobulin. For this purpose, the immunocomplexes obtained by direct precipitations are incubated for 1 $\mathrm{hr}$ at room temperature in a small volume (usually 30 to $50 \mu \mathrm{l}$ ) of $0.1 M$ Tris $\mathrm{HCl}, \mathrm{pH} 8.0$, containing $2 \%$ dodecylsulfate and $2 \%$ mercaptoethanol.

The heavier double immunoprecipitates may be treated in a similar way. To solubilize them in a small volume $(50 \mu \mathrm{l})$, however, the dodecylsulfate concentration should be increased to $5 \%$. Often it seems favor- 


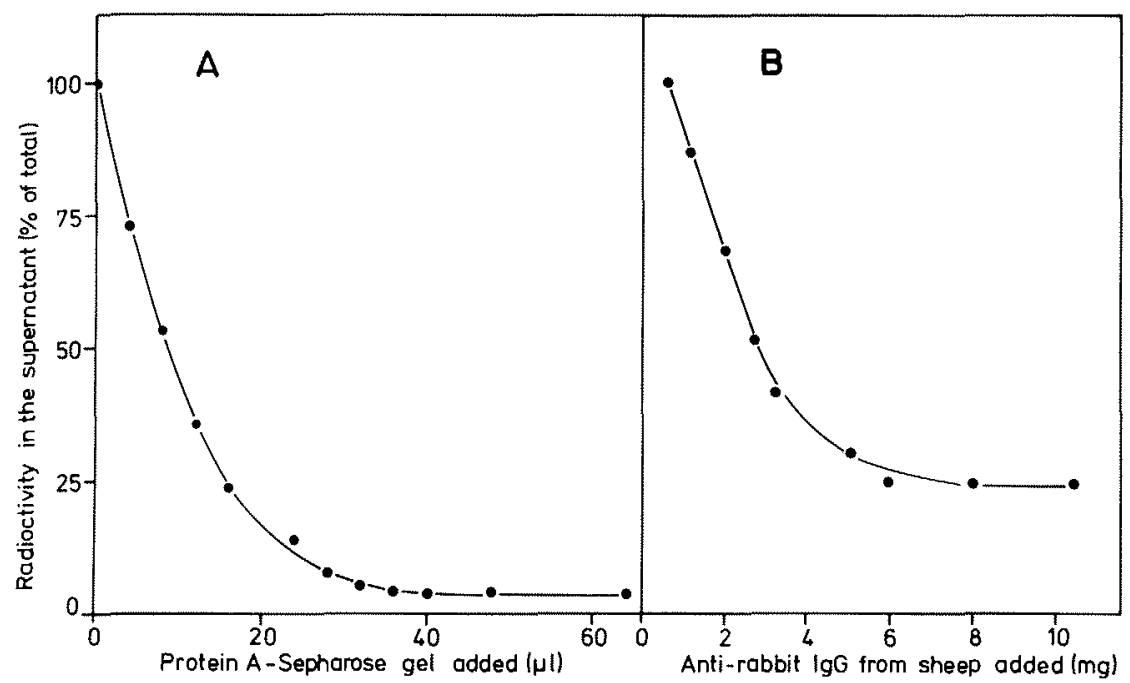

Figure 3. Titrations of ${ }^{3} \mathrm{H}$-labeled rabbit $\mathrm{IgG}$ in the presence of $2 \%$ Triton $\mathrm{X}-100$. $120-\mu \mathrm{g}$ aliquots of ${ }^{3} \mathrm{H}$-labeled IgG (specific radioactivity 15,700 counts $\times \mathrm{min}^{-1} \times(\mathrm{mg}$ $\mathrm{IgG})^{-1}$ ) were dissolved in $0.1 \mathrm{M}$ phosphate buffer, $\mathrm{pH} 8.0$, containing $2 \%$ Triton $\mathrm{X}-100$ (final volume $1 \mathrm{ml}$, each), and increasing amounts of protein A/Sepharose $(A)$, or antirabbit immunoglobulin from sheep (B), were added. The mixtures containing protein A/Sepharose were shaken gently for $30 \mathrm{~min}$; the double-immunoprecipitation assays were incubated for $12 \mathrm{hr}$. Then, all samples were centrifuged and the supernatants were analyzed for radioactivity (Werner and Machleidt, 1978).

able to omit the addition of mercaptoethanol. In this case, the immunoglobulin is not split into light and heavy chains. The uncleaved IgG molecules (both from rabbit and from sheep), which constitute most of the total protein present in the double immunoprecipitate, can no longer enter the highly crosslinked polyacrylamide gels and, therefore, prevent a possible overloading of the gels. Such a "separate analysis" of the antigen without interfering antibody might be desirable also if the electrophoretically resolved components are subsequently made visible by staining and not by the analysis of their radioactivity. In order to release the antigen (together with the antibody) from the protein A/Sepharose support, it is incubated $3 \mathrm{hr}$ at room temperature in Tris buffer $(0.1 M, \mathrm{pH} 8.0)$, containing $2,5 \%$ dodecylsulfate. For large-scale work using a support with covalently linked immunoglobulin a lower dodecylsulfate concentration $(1 \%)$ is applied to elute the attached antigen. In this case, the support can be reused for further isolation procedures. The capacity of the gel for antigen binding, however, drops to about $50 \%$ compared to its first application (Werner and Machleidt, 1978). This is obviously due to the treatment of the support 
with the relatively high dodecylsulfate concentration needed for the dissociation of the antibody-antigen linkage. Attempts to replace the detergent with other agents, such as guanidinium hydrochloride, have been unsuccessful, since both binding and dissociation of the membrane antigens are negatively affected. Furthermore, the "classical" acid treatment for antibody-antigen dissociation causes an irreversible aggregation of most membrane proteins and therefore can be applied only in special cases.

The electrophoresis is performed on horizontal slab gels $(12.5 \%$ or $15 \%$ acrylamide plus $1 / 30$ bisacrylamide) polymerized in $1 \%$ dodecylsulfate. The gels (size $0.35 \times 8.7 \times 20 \mathrm{~cm}$ ) have three slots for each $25-\mu \mathrm{l}$ sample. Tris- $\mathrm{HCl}$ buffer $(0.1 \mathrm{M}, \mathrm{pH} 8.0$, containing $1 \%$ dodecylsulfate) serves as the electrode buffer. For determination of the radioactivity of precipitated membrane components, the gels are cut into $1-\mathrm{mm}$ slices, and the protein is eluted by shaking each slice in 0.2 to $0.5 \mathrm{ml}$ of electrophoresis buffer overnight at $70^{\circ} \mathrm{C}$. An appropriate amount of scintillation cocktail is then added and the radioactivity is determined in a liquid scintillation counter.

\section{APPLICATION OF IMMUNOREACTIONS FOR BIOGENETIC STUDIES ON MITOCHONDRIAL MEMBRANES}

\section{Specific Content of Defined Membrane Components in Mitochondria}

The amount of cytochrome oxidase present in mitochondrial membranes can be calculated from data supplied by a titration experiment similar to that shown in Figure 2 (see Section II.3.C.a).

Neurospora cells were labeled uniformly with $\left[{ }^{14} \mathrm{C}\right]$ leucine. Mitochondria were isolated and submitochondrial particles, which reflect the insoluble membrane protein, were prepared by sonication and highspeed centrifugation (Werner, 1974). The membrane protein was solubilized with Triton X-100 and increasing amounts of the extract were added to a constant amount of anticytochrome oxidase immunoglobulin. A maximum of precipitation occurs at the equivalence point of the system. From the ${ }^{14} \mathrm{C}$-radioactivity found in this particular immunoprecipitate the amount of oxidase was estimated. Under optimal conditions $8.7 \%$ of the membrane protein could be precipitated with the antibody applied. This value agrees very well with the data obtained from spectrophotometric determinations of the cytochrome $a a_{3}$ content of mitochondrial membranes (Weiss et al., 1971, v. Jagow et al., 1973).

Components like the mitochondrial ATPase complex do not contain pigments and, therefore, the determination of these proteins cannot be 


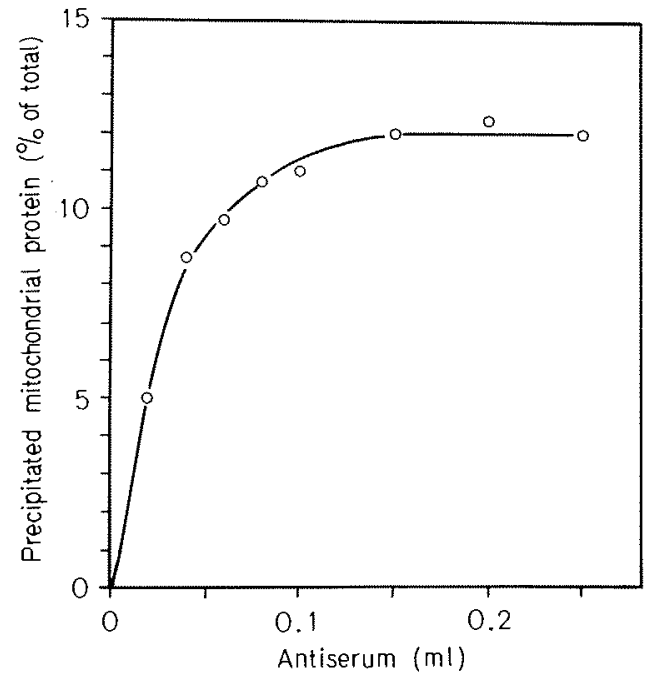

Figure 4. Titration of solubilized mitochondrial proteins with antiserum against $F_{1}$ - ATPase. Increasing amounts of antiserum were added to a constant amount of mitochondrial protein (specific radioactivity $140,000 \mathrm{cpm} / \mathrm{mg}$ ) prepared from cells labeled uniformly with $\left[{ }^{14} \mathrm{C}\right]$ leucine. The ordinate documents the precipitated labeled protein as a percentage of total mitochondrial protein.

performed spectrophotometrically. On the other hand, quantitative deierminations via the enzymatic activity (if present) may be riddled with considerable errors. In this situation, the quantitative immunoprecipitation offers an excellent approach to obtain reliable values (Jackl and Sebald, 1975; Sebald and Wild, 1979).

Figure 4 shows the titration of a constant amount of mitochondrial proteins labeled in vivo with $\left[{ }^{14} \mathrm{C}\right]$ leucine with increasing amounts of an antiserum to $\mathrm{F}_{1}$-ATPase of Neurospora. At optimal conditions (large excess of antibody), the antiserum precipitates about 12 to $15 \%$ of the whole mitochondrial protein. The high specificity of the two immune reactions mentioned was judged by electrophoretic analysis of the immunoprecipitates, revealing the characteristic radioactivity patterns for ATPase and cytochrome oxidase.

\section{Assessment of Precursor Pools of Cytochrome Oxidase}

To elucidate the highly complex formation of a supramolecular membrane unit like cytochrome oxidase, information about the provision of its individual constituents is first required. Detailed data on the kinetics of synthesis and processing of the individual polypeptide 
subunits of cytochrome oxidase are supplied by experiments involving radioactive pulse-chase-labeling of mitochondrial proteins and the subsequent isolation and analysis of the enzyme complex assembled in the membrane.

The Neurospora cell protein was labeled uniformly with $\left[{ }^{14} \mathrm{C}\right]$ leucine. Then $\left[{ }^{3} \mathrm{H}\right]$ leucine was added to the culture. After $1 \mathrm{~min}$ the culture was chased with unlabeled leucine. At different times after addition of $\left[{ }^{3} \mathrm{H}\right]$ leucine, samples of the culture were harvested and mitochondria were prepared.

Figure 5A shows the time course of ${ }^{3} \mathrm{H}$-labeling of the total mitochondrial membrane protein. The increase in specific radioactivity is reflected by the ${ }^{3} \mathrm{H} /{ }^{14} \mathrm{C}$ ratios measured in the protein fractions. Labeling of the membrane protein occurred very rapidly. The incorporation of $\left[{ }^{3} \mathrm{H}\right]$ leucine was completed after 2 to $3 \mathrm{~min}$. The ${ }^{3} \mathrm{H} /{ }^{14} \mathrm{C}$ ratio of the total membrane reached at that time did not change upon further incubation. A half-maximal labeling time of only $45 \mathrm{sec}$ was obtained for the membrane protein. This value gives one an idea of the rapidity of the cellular processes involved, for instance, the leucine uptake by the cells, the synthesis of polypeptide chains on the ribosomes, and the insertion of the newly translated products into the membrane.

For the continuation of the analysis the mitochondrial membrane preparations were solubilized with Triton $\mathrm{X}-100$ and then treated with anticytochrome oxidase $\gamma$-globulin. Figure $5 \mathrm{~B}$ shows the time curve of labeling for the oxidase precipitated from the membranes. Labeling of the cytochrome complex occurred much more slowly compared with the total membrane protein. This time, the incorporation reached its final value as late as $60 \mathrm{~min}$ after the pulse. The half-maximal labeling time for cytochrome oxidase was about $9 \mathrm{~min}$.

How can this discrepancy in the labeling of both total membrane protein and of the cytochrome complex be explained? An answer to this question is given by the labeling kinetics of the individual polypeptide subunits of the enzyme.

Figure 6 exhibits some of the electrophoretic analyses of the immunoprecipitates obtained with anticytochrome oxidase $\gamma$-globulin (Werner, 1974). The distribution patterns of the ${ }^{14} \mathrm{C}$ radioactivity were fairly constant. The characteristic seven subunit bands were observed. Surprisingly enough, the rate of labeling with $\left[{ }^{3} \mathrm{H}\right]$ leucine was not the same for all polypeptide subunits. Large differences existed. Whereas subunit 3 was labeled maximally $5 \mathrm{~min}$ after the addition of $\left[{ }^{3} \mathrm{H}\right]$ leucine, subunits 7 and 2 , for example, exhibited only a halfmaximal labeling at this time. This is in contrast to further findings 


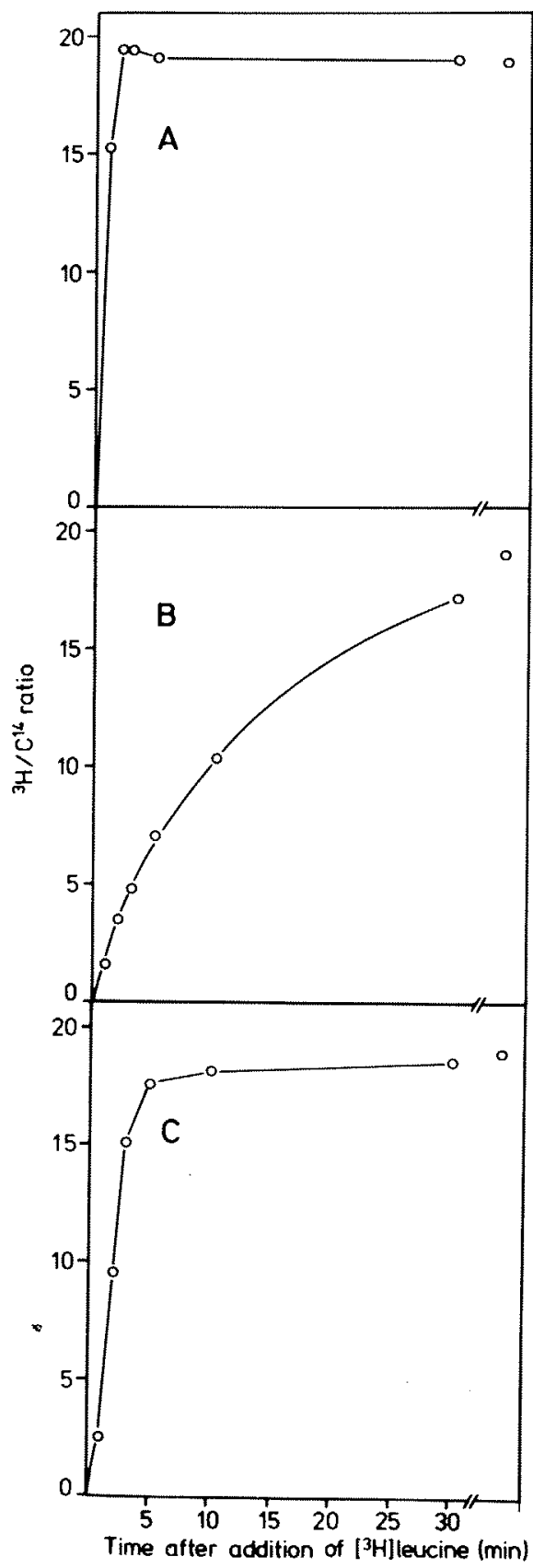

Figure 5. Time course of labeling of total mitochondrial protein (A), of immunoprecipitated cytochrome oxidase (B), and of subunit 3 in immunoprecipitated cytochrome oxidase (C) after pulse-labeling of cells. For experimental details see text. 


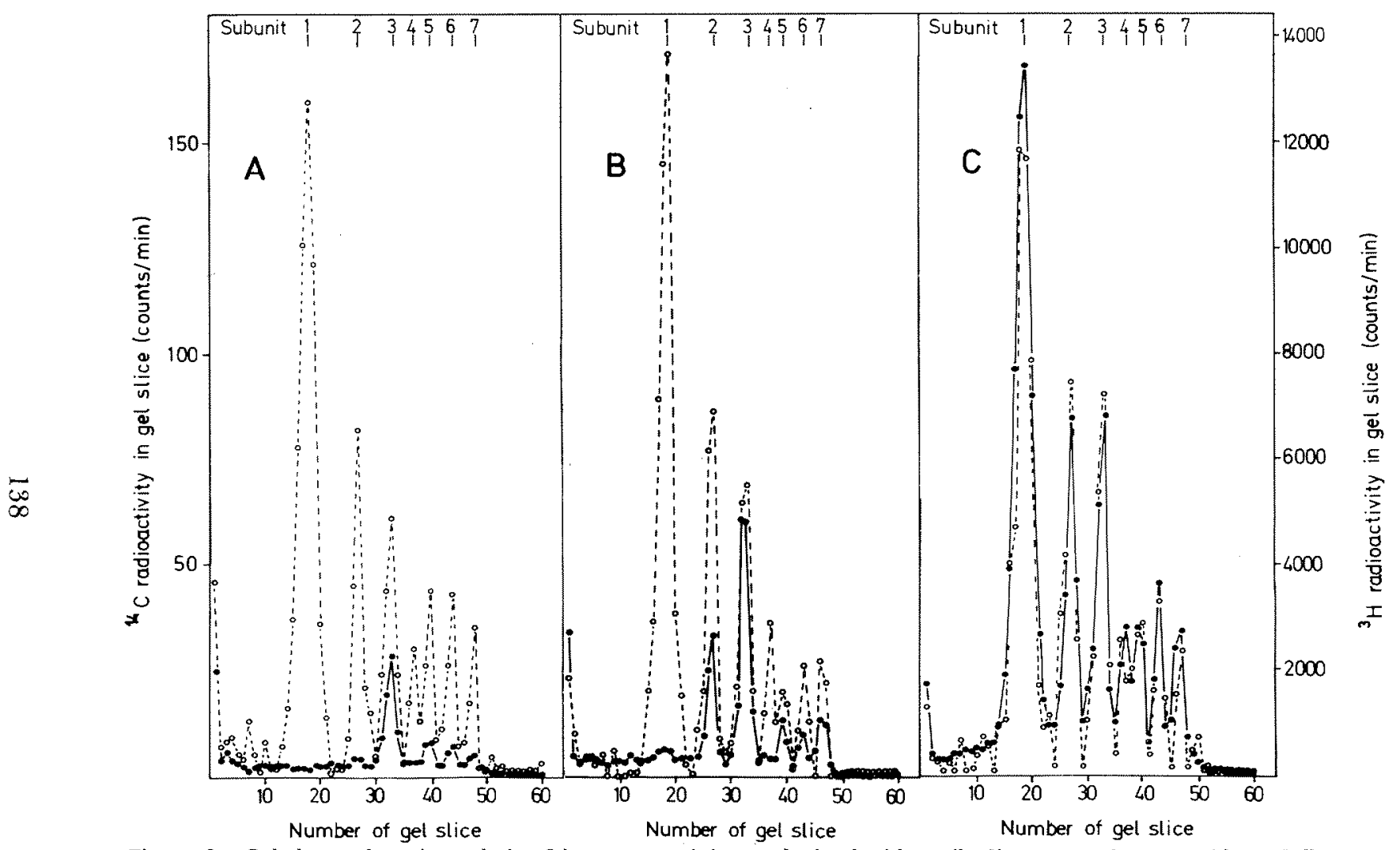

Figure 6. Gel-electrophoretic analysis of immunoprecipitates obtained with antibodies to cytochrome oxidase. Cells were incubated for $3 \mathrm{hr}$ with $\left[{ }^{14} \mathrm{C}\right]$ leucine. Then $\left[{ }^{3} \mathrm{H}\right]$ leucine was added. One min later the culture was chased with leucine. At different times after addition of $\left[{ }^{3} \mathrm{H}\right]$ leucine, samples of the culture were harvested. Mitochondria were prepared, solubilized with Triton $\mathrm{X}-100$, and treated with anticytochrome oxidase $\gamma$-globulin. Three of the immunoprecipitates are shown: (A) $2 \mathrm{~min}$, (B) $5 \mathrm{~min}$, (C) $60 \mathrm{~min}$ after addition of $\left[{ }^{3} \mathrm{H}\right]$ leucine. (-) ${ }^{3} \mathrm{H},(\mathrm{O} \ldots \mathrm{O}){ }^{14} \mathrm{C}$ radioactivity (Werner, 1974). 
obtained with subunits 1 and 4 . These components showed an extremely delayed labeling. The amount of ${ }^{3} \mathrm{H}$-radioactivity in these polypeptides, however, increased upon further incubation-at different rates-and at least $60 \mathrm{~min}$ after pulse-labeling all components had reached the same constant ${ }^{3} \mathrm{H} /{ }^{14} \mathrm{C}$ ratio. The observed ratio was in agreement with that obtained with the total membrane protein, although the labeling of each polypeptide subunit of cytochrome oxidase had followed a different time course.

On the assumption that an equally high translation rate of all proteins in exponentially growing cells occurs, the above results indicate that the oxidase is assembled from pools of free subunits (see also Figure 13). The pool sizes of the individual precursors are different, which accounts for the different delays in the labeling of the various polypeptide subunits of the enzyme complex. Consequently, the size of a precursor pool can be calculated from the labeling kinetics of the corresponding enzyme subunit (Schwab et al., 1972). Since there is no protein breakdown and since no turnover of cytochrome oxidase could be detected in exponentially growing Neurospora cells (Schwab et al., 1972), the turnover rate of the precursor is equal to the net rate of appearance of the oxidase subunit. The total cell mass doubles in about $200 \mathrm{~min}$, and therefore, the total amount of cytochrome oxidase doubles in the same time. The ratio of the amount of the precursor to that of the corresponding subunit will then be equal to the ratio of the half-life of the precursor to the doubling time of the whole cell. In the event that only one pool exists for a given subunit, the half-life of the precursor protein can be estimated by the following differences in the times needed for half-maximal labeling of whole membrane protein and subunit (Schwab et al., 1972): $t_{1 / 2}$ (precursor) $=t_{1 / 2}$ (subunit) $-t_{1 / 2}$ (membrane protein). An example is given for subunit 3 of the oxidase.

Figure 5C shows the labeling kinetics of this subunit provided by the electrophoretic analysis of the immunoprecipitated cytochrome oxidase. The time for half-maximal labeling of subunit 3 was only 135 sec. On the other hand, the corresponding time for the total membrane protein was $45 \mathrm{sec}$. Thus, a half-life of $90 \mathrm{sec}$ can be calculated for the precursor.

\section{Site of Translation of Mitochondrial Polypeptides}

The formation of a mitochondrial membrane fully competent in electron transfer and oxidative phosphorylation requires the cooperation of cytoplasmic and mitochondrial protein synthesis. To identify the translation products of mitochondrial as well as of cytosolic ribosomes, 
specific inhibitors of the protein synthesis have been introduced. A selective labeling of proteins according to their translation site is achieved when cells are incubated with radioactive amino acids in the presence of either cycloheximide, a specific inhibitor of cytoplasmic translation, or chloramphenicol, a specific inhibitor of mitochondrial translation (see Section II.1.B.b).

Cellular proteins of a Neurospora culture were prelabeled uniformly with $\left[{ }^{14} \mathrm{C}\right]$ leucine. Then, cells were poisoned with cycloheximide. Two and one-half min after this treatment $\left[{ }^{3} \mathrm{H}\right]$ leucine was added to the culture. After $45 \mathrm{~min}$ of incubation the cells were harvested and mitochondria were prepared. The mitochondria were solubilized with Triton X-100 and the extract was divided into two equal portions. To one half antiserum A was added, and the second half of the solubilized mitochondria was treated with antiserum B. Both antiserums were directed specifically against cytochrome oxidase of Neurospora crassa, obtained, however, from different rabbits. Figure 7 shows the analysis of the immunoprecipitates. The distribution of the ${ }^{14} \mathrm{C}$-radioactivity in the two gels, reflecting the seven polypeptide subunits of the oxidase, reveals that both antiserums are equally competent for the precipitation of the cytochrome complex. The patterns of the ${ }^{3} \mathrm{H}$-radioactivity, representing the cycloheximide resistant label in the oxidase are different. Whereas $\left[{ }^{3} \mathrm{H}\right]$ leucine was clearly incorporated into subunit 3 of the oxidase precipitated both with antiserum $A$ and antiserum $B$, a definite labeling of additional subunits (namely subunits 1 and 2) was found only in the oxidase isolated with antiserum B. Thus, the latter experiment supplies evidence that subunits 1,2 , and 3 of cytochrome oxidase are translated on mitochondrial ribosomes. In the other experiment using antiserum $\mathrm{A}$, however, the conclusion might be drawn only for the synthesis of subunit 3 .

The following explanation is given for the different results. Since cycloheximide immediately inhibits the cytosolic protein synthesis, the assembly process to a functioning oxidase can proceed only by the utilization of those cytosolically made subunits already present in the form of precursor pools (see Section III.2). Therefore, that particular cytoplasmic subunit exhibiting the smallest pool size becomes rate limiting for the assembly process. For these reasons, the formation of cytochrome oxidase ceases quickly. This means, however, that very little of the ${ }^{3} \mathrm{H}$-labeled mitochondrially synthesized partner subunits will be found in an assembled enzyme complex. Obviously, the pattern obtained with antiserum $\mathrm{A}$ (Figure $7 \mathrm{~A}$ ) results from the fact that the applied antibody recognizes exclusively the assembled oxidase under the given conditions. The high specific labeling of subunit 3 can be 


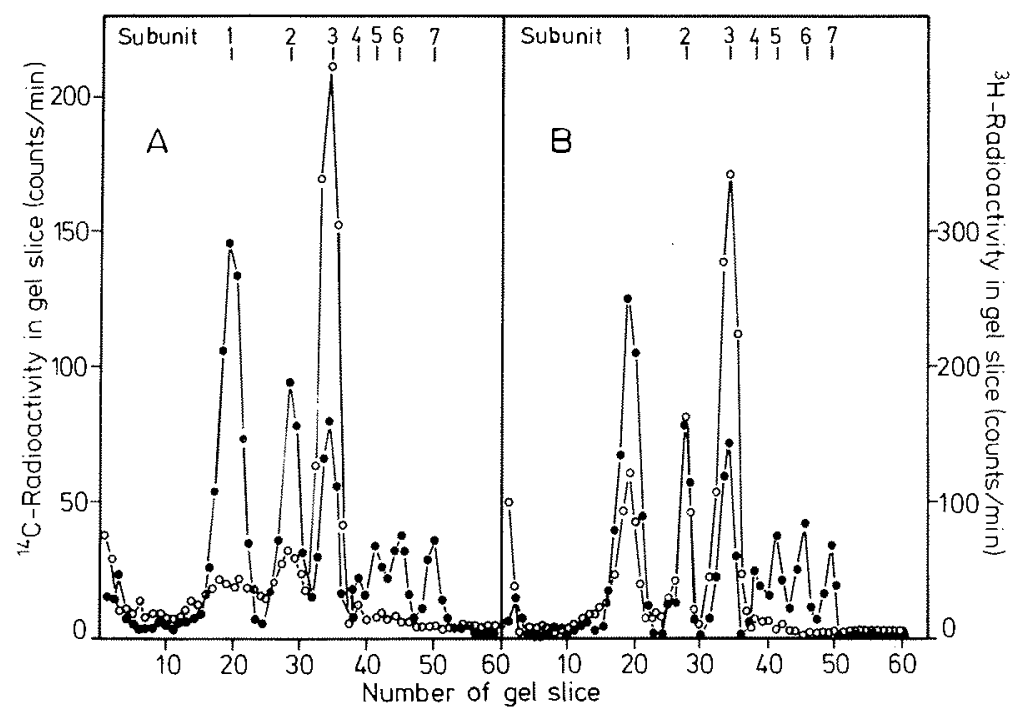

Figure 7. Gel electrophoretic analysis of immunoprecipitates obtained with two different anticytochrome oxidase serums. Cells were first labeled uniformly with $\left[{ }^{14} \mathrm{C}\right]$ leucine and then labeled specifically in the presence of cycloheximide with $\left[{ }^{3} \mathrm{H}\right]$ leucine. Mitochondria were prepared and one aliquot was treated with antiserum A (panel A) and another aliquot was treated with antiserum B (panel B), both directed against holocytochrome oxidase. $\left(\bullet-{ }^{14} \mathrm{C}\right.$ radioactivity, (O-O) ${ }^{3} \mathrm{H}$ radioactivity (Werner, unpublished results).

explained by the extremely small pool size of this mitochondrially made subunit (see Section III.2). In other words, a considerable part of the labeled "subunit 3 " precursor pool has a good chance to be used in the assembly process before it ceases. For subunits 1 and 2, on the other hand, relatively large pool sizes were found, so that the integration of labeled components into the "growing" protein complex can hardly occur.

A different situation is responsible for the pattern observed with antiserum B (Figure 7B). This antibody may precipitate not only the fully assembled enzyme complex, but also certain precursors, for instance incomplete assembled intermediates, because of the different antigenic determinants which are recognized by this antiserum. The lower specific labeling of subunits 1 and 2 compared to subunit 3 should reflect again the different dilution of the radioactivity by the different pool sizes of the individual "free" subunits.

This experiment demonstrates the difficulties of identifying mitochondrially synthesized products of oligomeric complexes merely on the basis of the specific labeling in the presence of cycloheximide. A 
substantial knowledge of labeling kinetics, as well as a characterization of the antibody used for the isolation of the products, are necessary.

A second approach for establishing the translation site of mitochondrial polypeptides is the incorporation of radioactive amino acids in the presence of chloramphenicol. Neurospora cells were uniformly prelabeled with $\left[{ }^{14} \mathrm{C}\right]$ leucine and then labeled specifically with $\left[{ }^{3} \mathrm{H}\right]$ leucine after adding chloramphenicol to the culture, as described in Section II.1.B.b. A direct immunoprecipitation was conducted with the isolated mitochondria using an antiserum to holocytochrome oxidase. Figure 8 shows the electrophoretic analysis of the precipitate. The distribution of the ${ }^{14} \mathrm{C}$-radioactivity displays again, as expected, seven bands corresponding to the oxidase subunits. On the other hand, the ${ }^{3} \mathrm{H}$-label is found in all seven subunits as well. The reason for the latter finding is the incomplete inhibitory effect of chloramphenicol (see also Section II. I.B.b). Nevertheless, after examination of the ${ }^{3} \mathrm{H} /{ }^{14} \mathrm{C}$ ratios of the

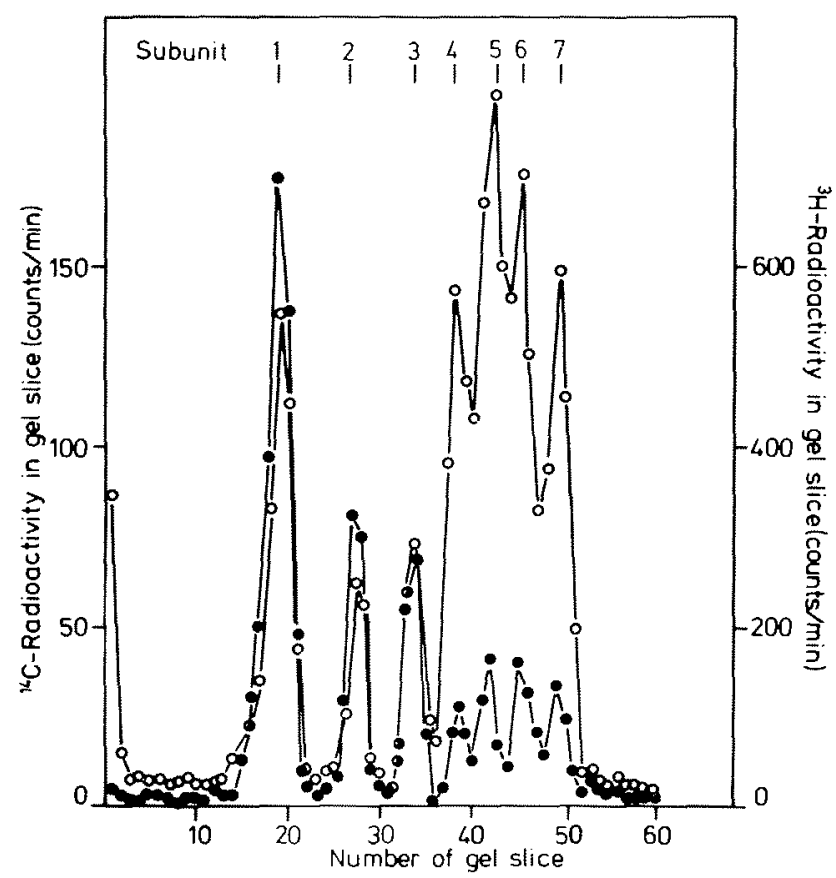

Figure 8. Gel electrophoretic analysis of an immunoprecipitate obtained with anticytochrome oxidase serum. Cells were first labeled uniformly with $\left[{ }^{14} \mathrm{C}\right] l$ leucine and then labeled specifically in the presence of chloramphenicol with $\left[{ }^{3} \mathrm{H}\right]$ leucine. Mitochondria were prepared, solubilized, and treated with the serum. $\left(\bullet-\bullet{ }^{14} \mathrm{C}\right.$ radioactivity, $\left(\mathrm{O}_{-}\right)^{3} \mathrm{H}$ radioactivity (Werner, unpublished results). 
individual enzyme subunits separated electrophoretically, it becomes evident that the specific ${ }^{3} \mathrm{H}$-label is accumulated in subunits 4 to 7 , a positive indication for their cytosolic origin. The fivefold higher ${ }^{3} \mathrm{H} /{ }^{14} \mathrm{C}$ ratio of subunits 4 to 7 compared to that of subunits 1 to 3 correlates with an $80 \%$ inhibition of mitochondrial protein synthesis by chloramphenicol. Moreover, this insufficiency of the drug effect ensures that the assembly process can proceed to a minimal extent and consequently the antibody against holocytochrome oxidase will precipitate an enzyme complex containing specifically labeled polypeptides.

In summary, the "complementary" patterns of cytochrome oxidase subunits obtained by labeling in the presence of cycloheximide and chloramphenicol, lead one to the conclusion that subunits 1 to 3 are synthesized on mitochondrial ribosomes, whereas subunits 4 to 7 are translated on cytosolic ribosomes. We want to emphasize, however, that the experimental results are not always as easy to interpret as those obtained for the oxidase. Principally, one should keep in mind that a negative result for labeling of a polypeptide in the presence of an inhibitor cannot be used as an argument for locating the translation site of the component. In this case, the goal is reached only by discerning whether the polypeptide at hand is not synthesized, or whether it is indeed synthesized, but is not present in a precipitable form.

This brings us again to the specificity of the employed antibodies raised against oligomeric membrane complexes. One possible way out of the dilemma may be the application of modified incubation techniques, which allow the assembly of precursors synthesized (and labeled) in the presence of inhibitors (Jackl and Sebald, 1975). The following examples should illustrate this suggestion.

Rabbits were injected with the $F_{1}$-portion of ATPase isolated from Neurospora mitochondria. The produced antibody had precipitated the whole ATPase complex containing 14 polypeptide subunits from solubilized mitochondria (compare also Section III.1). Treatment of cells with cycloheximide strongly inhibited amino acid incorporation into all polypeptides precipitated with the antiserum to $\mathrm{F}_{1}$-ATPase (Figure 9A). Label appeared in components 9 and 13, but the amounts varied from experiment to experiment and no enrichment was observed when compared to the label of whole mitochondrial protein. On the other hand, it was demonstrated that the cycloheximide-resistant amino acid incorporation could be stimulated after a transitory incubation of the cells with chloramphenicol (Jackl and Sebald 1975). Indeed, after such a specific pretreatment (see also Section II.1.B.b) the label was found to be enhanced in whole mitochondrial protein and to a still larger extent in components 9 and 13 of the ATPase (Figure 9B). The specific 


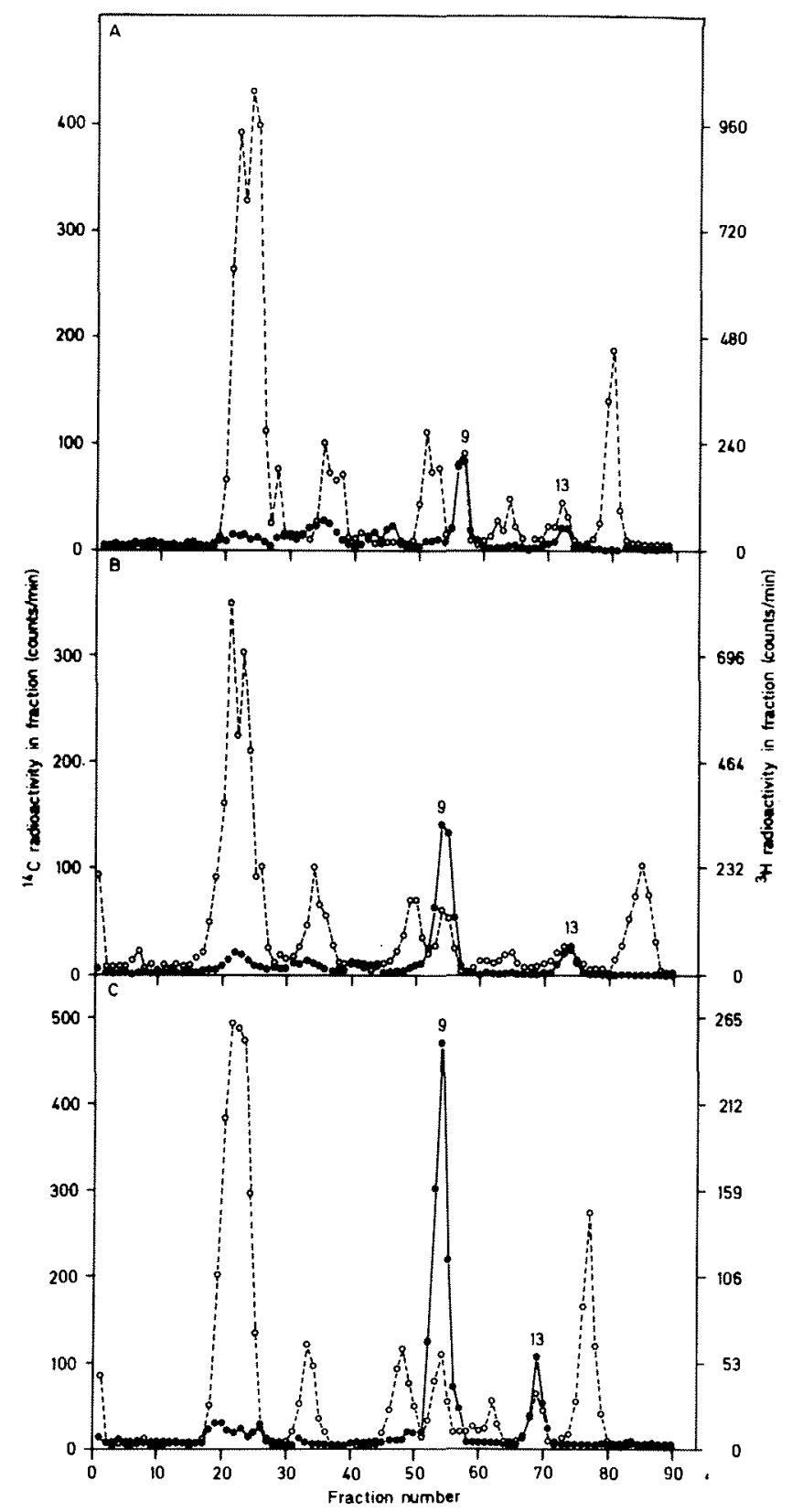

Figure 9. Cycloheximide-resistant label in immunoprecipitated ATPase complex after different labeling procedures. $\left(\mathrm{O}_{---O}\left[{ }^{14} \mathrm{C}\right]\right.$ leucine control label; $(\bullet-\bullet),\left[{ }^{3} \mathrm{H}\right]$ leucine incorporated in the presence of cycloheximide (A) over a labeling period of $60 \mathrm{~min}$, (B) over a labeling period of $60 \mathrm{~min}$ after a transitory incubation with chloramphenicol and $(C)$ over a labeling period of 2 min plus a 60 -min chase after a transitory incubation with chloramphenicol. The ATPase complex was isolated by immunoprecipitation with antiserum to $F_{1}$-ATPase and separated by dodecylsulfate gel electrophoresis. The scales of the ${ }^{3} \mathrm{H}$ and ${ }^{14} \mathrm{C}$ radioactivities in the ordinates were drawn in the same relations as the ${ }^{3} \mathrm{H} /{ }^{14} \mathrm{C}$ ratios determined for whole mitochondrial protein $(\mathrm{A}: 2.4 ; \mathrm{B}: 2.32 ; \mathrm{C}: 0.53)$. The numbers above the radioactivity bands indicate components of ATPase (Sebald and Jackl, 1975). 
radioactivity of component 9 was enriched 2.4-fold compared to whole mitochondrial protein, after labeling the chloramphenicol-pretreated cells for $60 \mathrm{~min}$ in the presence of cycloheximide (Figure 9B). The highest specific radioactivity was found in components 9 and 13 after a transitory incubation of cells with chloramphenicol followed by a pulse-chase-labeling in the presence of cycloheximide (Figure 9C).

There are two possible reasons for the stimulatory effect of the chloramphenicol preincubation: (1) In the presence of chloramphenicol the pools of the cytoplasmically synthesized subunits may increase. Subsequently, the assembly of the ATPase complex can proceed for a longer period in the presence of cycloheximide. (2) The pools of the mitochondrially synthesized subunits may decrease during the chloramphenicol treatment, and therefore, the polypeptides synthesized in the presence of cycloheximide appear more rapidly in the ATPase complex. Whatever the actual interpretation may be, the above findings do indicate the presence of mitochondrial translation products in the ATPase components 9 and 13.

This view is strongly supported by the "complementary" experiment which should lead to a predominant labeling of the cytoplasmically made portion of the ATPase complex. After inhibition of the mitochondrial protein synthesis by chloramphenicol ${ }^{3} \mathrm{H}$-label was found to be incorporated into all polypeptides of the oligomeric protein, but to a much smaller extent into the components 9 and 13 (Figure 10A). In order to learn whether the poor labeling of these two components is due to an inhibition of its synthesis chloramphenicol was removed from the culture after the labeling period and the cells were grown for another hour in fresh medium (see Section II.1.B.b). The labeling of whole mitochondrial protein is not affected by this procedure (Jackl and Sebald, 1975). Figure 10B shows that the specific label increased in most of the polypeptides of the ATPase, but did not in components 9 and 13 . In this case, the $90 \%$ and the $50 \%$ inhibition of the respective labeling, calculated from the above experiment, persists, which must be considered good evidence for the mitochondrial origin of these two components. Most probably the other polypeptides were synthesized in the presence of chloramphenicol, but not assembled into the ATPase complex until the mitochondrial protein synthesis had been restored.

All these more or less complicated procedures designed to solve the assembly problem of newly synthesized polypeptides brought about by the action of the particular inhibitor, can be avoided if one succeeds in directly isolating the involved precursor polypeptides. A prerequisite for such an approach, however, is the availability of specific antibodies against individual polypeptide subunits. Detailed investigations have 


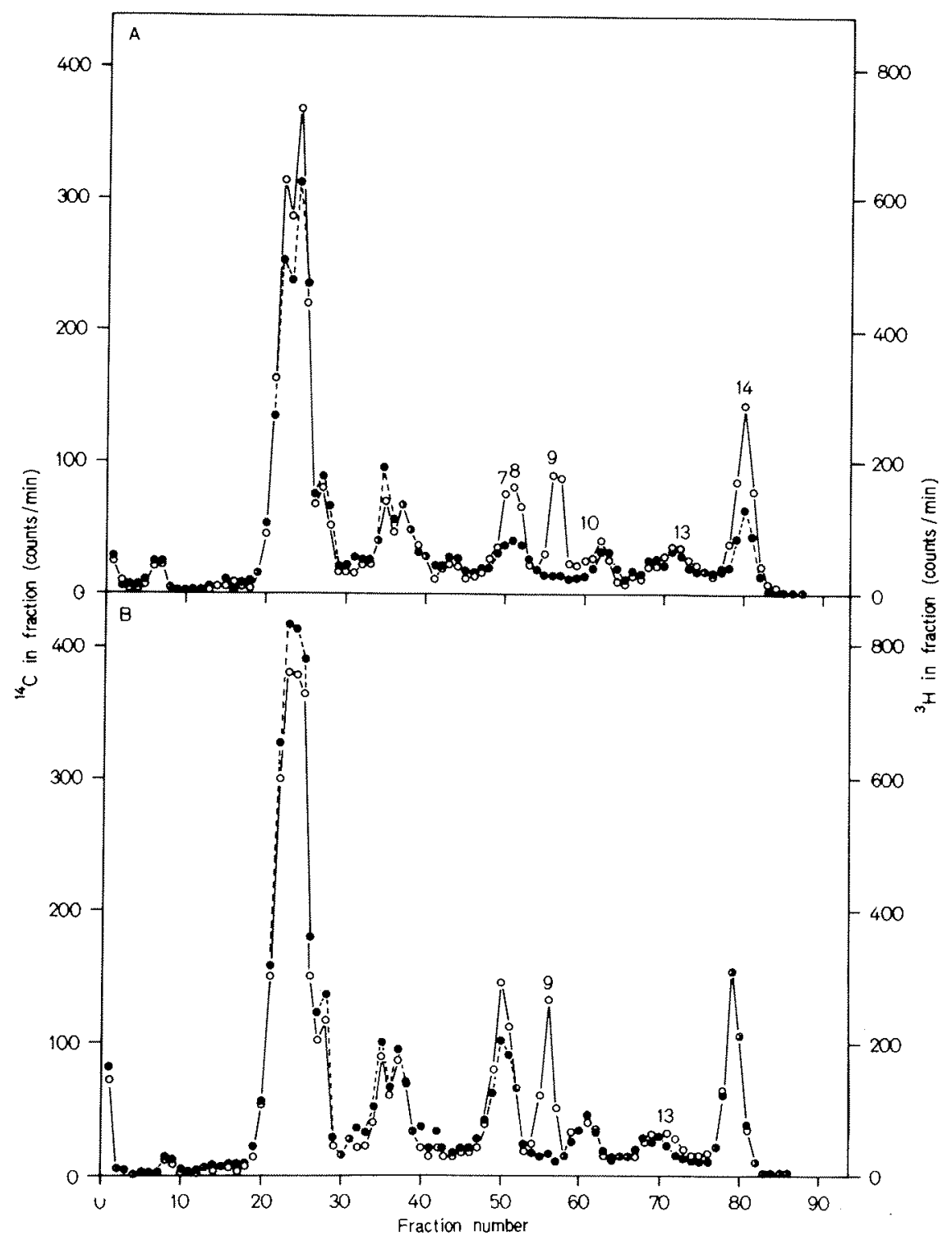

Figure 10. Recovery of chloramphenicol-resistant label in immunoprecipitated ATPase complex before and after washing out the inhibitor. $\left({ }^{\circ}-.-O\right),\left[{ }^{14} \mathrm{C}\right]$ leucine control label; $(\bullet-\bullet),\left[{ }^{3} \mathrm{H}\right]$ leucine incorporated during a 30 -min labeling period in the presence of chloramphenicol (A) before and (B) after washing out of chloramphenicol and further growth of the cells. The ATPase complex was isolated by immunoprecipitation with antiserum to $\mathrm{F}_{1}$-ATPase and separated by dodecylsulfate gel electrophoresis. The scales of the ${ }^{3} \mathrm{H}$ and ${ }^{14} \mathrm{C}$ radioactivities in the ordinates were drawn in the same relations as the ${ }^{3} \mathrm{H} /{ }^{14} \mathrm{C}$ ratios determined for whole mitochondrial protein ( $\mathrm{A}$ and $\mathrm{B}, 2.0$ ). The numbers above the radioactivity bands indicate components of ATPase (Sebald and Jackl, 1975). 
been conducted on subunits of cytochrome oxidase, some of which are presented in the following paragraph.

To establish the translation site of precursor polypeptides of cytochrome oxidase in Neurospora, cells were first labeled with radioactive amino acids in the presence of cycloheximide or chloramphenicol as outlined at the beginning of this section. Following this, unassembled subunits were isolated individually from mitochondrial preparations by means of subunit-specific antibodies using the double immunoprecipitation technique (see Section II.3.C.b). When the mitochondrial protein synthesis had been inhibited by chloramphenicol, no significant label was found in the precipitates obtained with immunoglobulins against subunit 1 , subunit 2 , or subunit 3 . On the other hand, preincubation with cycloheximide resulted in the isolation of labeled polypeptides when the same antibodies were employed. Figure 11 summarizes the electrophoretic analysis of these immunoprecipitates. The ${ }^{3} \mathrm{H}$-radioactivity representing the cycloheximide-resistant label migrates as one major band and it coincides with the corresponding marker subunit of an assembled enzyme.

Additional information on the isolated precursor polypeptides can be drawn from their kinetic behavior. As an example of this the time course of the labeling for unassembled subunit 3 is shown (Figure 12). The kinetic plot demonstrates clearly that the labeled polypeptide does not disappear during further incubation in the presence of cycloheximide. The incorporation of the radioactivity into the precursor increases continuously for $30 \mathrm{~min}$, a good indication for the blocked assembly process of the oxidase under these conditions

\section{Isolation of Precursors of Cytochrome Oxidase in Wild-Type and in Cytochrome Oxidase Deficient Cells}

The experiments described in the prior paragraph demonstrate the merits of subunit-specific antibodies for the isolation of individual unassembled polypeptide components of cytochrome oxidase. Proof is needed, however, that these polypeptides behave like genuine precursors of the oxidase if the assembly process is no longer blocked as resulted from the application of inhibitors of the protein synthesis. The preferable labeling method for tracing the fate of the translation products is the pulse-chase-labeling of polypeptides with radioactive leucine (see Section II.1.A.b).

Figure 13 provides an outline of the route of the leucine from its injection into the cell culture to the incorporation into the assembled enzyme. The diagram also includes the information on the different 


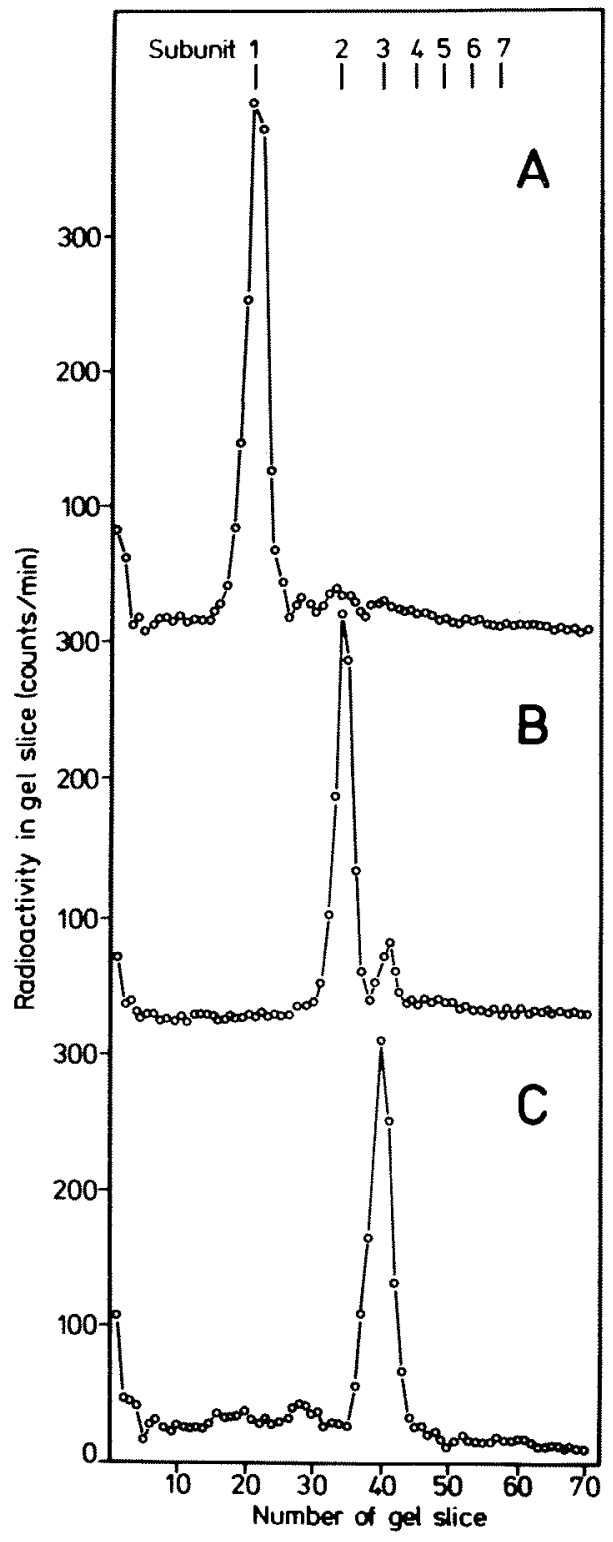

Figure 11. Immunological isolation of unassembled mitochondrially synthesized polypeptides of cytochrome oxidase. Cells were labeled in the presence of cycloheximide with $\left[{ }^{3} \mathrm{H}\right]$ leucine. Mitochondria were prepared and aliquots were treated with (A) antisubunit $1 \gamma$-globulin, (B) antisubunit 2 $\gamma$-globulin and (C) antisubunit $3 \gamma-$ globulin from rabbit. An antirabbit $\gamma$ globulin from sheep was added to the samples. The precipitates obtained were analyzed with gel electrophoresis. The gels were calibrated with ${ }^{14} \mathrm{C}$-labeled marker subunits of cytochrome oxidase (Werner, unpublished results). 


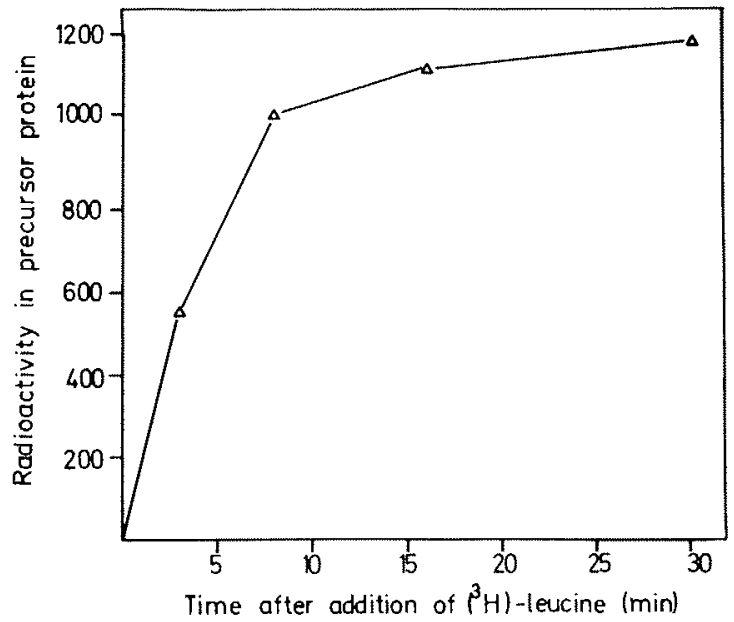

Figure 12. Time course of labeling of unassembled subunit 3 of cytochrome oxidase precipitated from cells labeled in the presence of cycloheximide (Werner, 1974).

translation sites of the polypeptide components (see Section II.3), as well as on the pool size of the individual subunit precursors calculated from the indirect data obtained by the experimental procedure outlined in Section II.2.

In this instance, we tried to isolate the pulse-labeled translation products at two different stages of the enzyme formation: (1) as oxidase subunits integrated into the assembled enzyme complex; this was achieved in the same way as described in Section II.2, using an

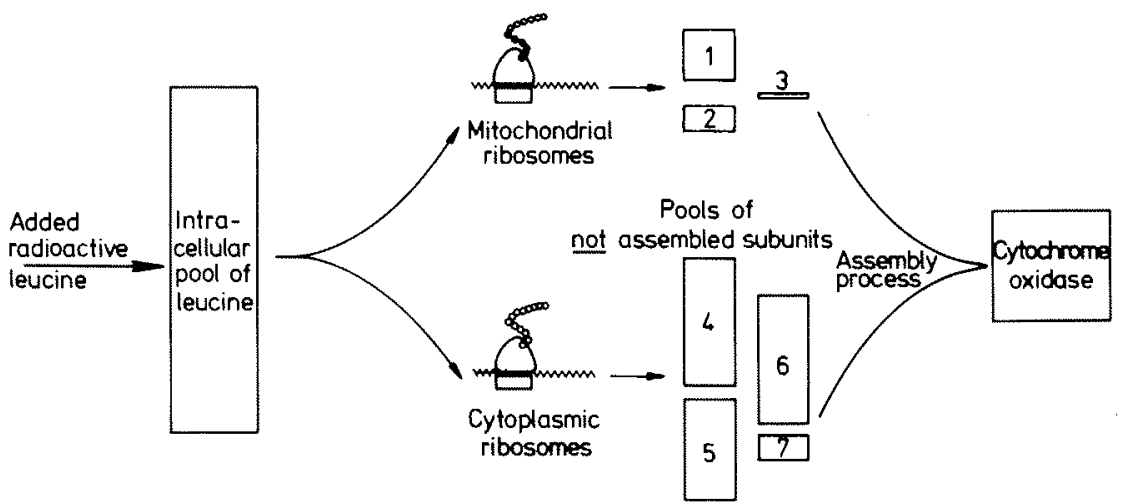

Figure 13. Schematic presentation of the formation of cytochrome oxidase. Route of the radioactive leucine in the course of enzyme biosynthesis. 
antibody against holocytochrome oxidase, and (2) as individual, "free" (i.e., unassembled) subunits forming precursor pools, by means of subunit-specific antibodies. A typical experiment involving the mitochond rially synthesized subunit 3 of the oxidase is presented.

Neurospora cells were labeled uniformly with $\left[{ }^{14} \mathrm{C}\right]$ leucine. Then, a 1-min pulse with $\left[{ }^{3} \mathrm{H}\right]$ leucine was applied followed by a chase with unlabeled leucine. Immediately thereafter, samples were taken from the culture at distinct time intervals and they were rapidly harvested using a freeze-stop technique (Werner, 1974). Mitochondria were prepared and aliquots were treated with specific $\gamma$-globulin to subunit 3 . This antibody did not precipitate holocytochrome oxidase. A detailed characterization of the immunological properties of this $\gamma$-globulin preparation is offered in Section II.3.B.a (see, for instance, Figure 1). The precipitate obtained by the double immune method was analyzed. No ${ }^{14} \mathrm{C}$-radioactivity could be detected in the immunoprecipitations isolated from the samples harvested during the entire time period. The amount of ${ }^{3} \mathrm{H}$-radioactivity found in the precipitates, however, rapidly increased within the first minutes after pulse-labeling, reached a maximum after about $2.5 \mathrm{~min}$, and subsequently decreased to low readings (Figure 14). The radioactive material precipitated was subjected to gel electrophoresis and one major peak was observed coinciding with the marker subunit 3 of the oxidase (Werner, 1974).

Other aliquots of the isolated mitochondria were treated with an antibody against holocytochrome oxidase and the assembled enzyme was precipitated (see Section II.2). From this experiment, essentially the same kinetics were obtained for subunit 3 integrated in an oxidase complex as those already shown in the plot of Figure $5 \mathrm{C}$ (Section II.2). Now, if we recall that both curves exhibited in Figures 5C and 14 reflect the labeling kinetics of mitochondrially synthesized polypeptides (see Section II.3) of the same apparent molecular weights-one polypeptide present anywhere in the mitochondrial membrane and the other present in cytochrome oxidase-the conclusion can be drawn that the polypeptide isolated with the subunit 3-specific antibody represents the precursor polypeptide of the enzyme subunit 3, a polypeptide component not yet integrated into the oxidase complex. The labeling kinetics of the precursor (Figure 14) supply direct information on the turnover rate of this polypeptide. The time elapsed until $50 \%$ of the labeled precursor has disappeared should be equivalent to its half-life. Since it is difficult to determine precisely the maximum of labeling, the curve was plotted semilogarithmically. A half-life of about 2 to $3 \mathrm{~min}$ was obtained, a value in fairly close agreement with the half-life 


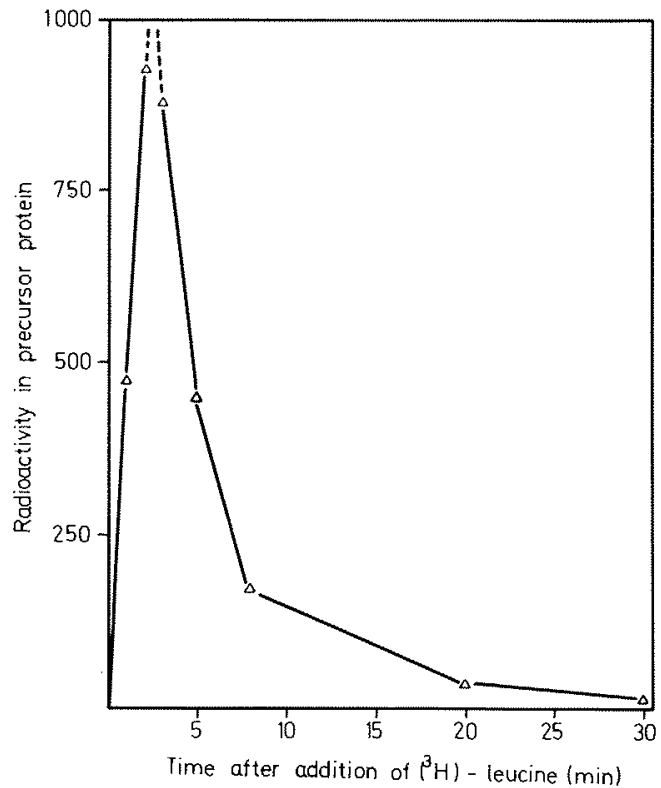

Figure 14. Time course of labeling of a precursor of cytochrome oxidase precipitated with an antisubunit $3 \gamma$-globulin (Werner, 1974).

calculated from the indirect data (half-maximal labeling kinetics of end products) given in Section III.2.

To determine whether the pool of the precursor polypeptide is located in the membrane or in the matrix portion of mitochondria, the isolated organelles were suspended in buffers of high ionic strength and submitted to sonic irradiation. After centrifugation, the precursor was completely recovered in the insoluble material. Obviously, the protein is tightly associated with mitochondrial membranes and cannot be removed by the above treatment.

For a quantitative evaluation of the precursor polypeptide, a leucine-deficient mutant of Neurospora crassa was employed. These cells were continuously labeled with $\left[{ }^{3} \mathrm{H}\right]$ leucine as described in Section II.1.A.b. Under these labeling conditions, all cellular proteins, including short-lived precursor proteins, should display the same specific radioactivity. Thus, the amount of precipitated precursor can be calculated directly from the radioactivity found in the immunoprecipitates or on the dodecylsulfate gels. Roughly $0.5 \mu \mathrm{g}$ of the subunit precursor was precipitated from $1 \mathrm{mg}$ of solubilized mitochondrial membranes. 
This means that the precursor represents about $0.05 \%$ of the total membrane protein.

One of the main difficulties with the isolation of cytochrome oxidase precursors in wild-type cells is caused by the rapid turnover of these polypeptides. A basically different situation exists in cytochrome oxidase deficient cells. In this case, the oxidase formation is blocked at a certain level, dependent on the underlying defect, and more or less "stable precursor" polypeptides are produced displaying the characteristics of end products. The appearance of these oxidase components has been studied in a number of nuclear and extranuclear mutants of Neurospora, deficient in cytochrome $a a_{3}$ (Werner et al., 1974; Klein et al., 1975; Bruckmooser and Werner 1976; Bertrand and Werner, 1977; Nargang et al., 1978; Bertrand and Werner, 1979; Nargang et al., 1979), as well as in copper-depleted wild-type cells (Werner et al., 1974). Since the defects leading to the oxidase deficiency in the mutants investigated to date seem to involve regulatory processes rather than structural genes of oxidase components, some of these cells may provide an excellent tool for the study of the genetic and biochemical control mechanisms of the enzyme assembly.

In connection with the appearance of individual precursor polypeptides of the oxidase, one mutant particularly attracted our attention. It is the maternally inherited mi-3 mutant of Neurospora crassa. The mutant shows the following features: (1) It lacks cytochrome $a a_{3}$ (Mitchell et al., 1953; Bertrand et al., 1976). (2) It is deficient in the subunit 2 polypeptide of the oxidase (Bertrand and Werner, 1977). (3) A mitochondrially made polypeptide is precipitated with a specific antibody to subunit 1 , displaying a higher apparent molecular weight than the corresponding wild-type product upon gel electrophoresis (Bertrand and Werner, 1979; Werner and Bertrand 1979). (4) The production of cytochrome $a a_{3}$ can be induced in the mutant by genetic and chemical blocks in the cytochrome $b c_{1}$ portion of the cytochrome chain (Bertrand and Collins, 1978). In this context, the observation of an "altered" mitochondrially translated polypeptide, which cross-reacts with specific antibodies to subunit 1 raises a number of questions, for instance, whether this polypeptide is an "incorrectly translated subunit," or whether it represents a naturally occurring precursor form of subunit 1 of the oxidase. The experimental approach devised to answer this question (Werner and Bertrand, 1979) will now be briefly introduced. The underlying concept takes advantage of the different specificity of the applied antibodies and makes use of the fact that the $m i-3$ mutant can be induced to synthesize a functional oxidase com- 
plex by the addition of small amounts of antimycin $\mathrm{A}$ to the culture medium (Bertrand and Collins, 1978).

Cells of the $m i-3$ mutant were pulse-chase-labeled with $\left[{ }^{3} \mathrm{H}\right]$ leucine and a portion of them were treated with antimycin $\mathrm{A}$ as indicated in the flow diagram shown in Figure 15. Cells were harvested at different times and mitochondria were prepared. One portion of each mitochondrial preparation was treated successively with antisubunit 1 immunoglobulin and protein A/Sepharose (see Section II.3.C.c). The precipitates were analyzed on dodecylsulfate gels after admixing ${ }^{14} \mathrm{C}$ labeled marker subunits of wild-type cytochrome oxidase. One major ${ }^{3} \mathrm{H}$-radioactivity band was observed in all control experiments without the application of antimycin (compare radioactivity pattern in Figure $16 \mathrm{~A})$. This mutant product migrated more slowly during gel electrophoresis than the authentic 41,000-dalton subunit 1 of the wild-type enzyme. An apparent molecular weight of about 45,000 was estimated for the cross-reacting mutant polypeptide (Werner and Bertrand, 1979). A similar radioactivity pattern was observed with immunoprecipitates obtained from cells incubated only for a short period in the

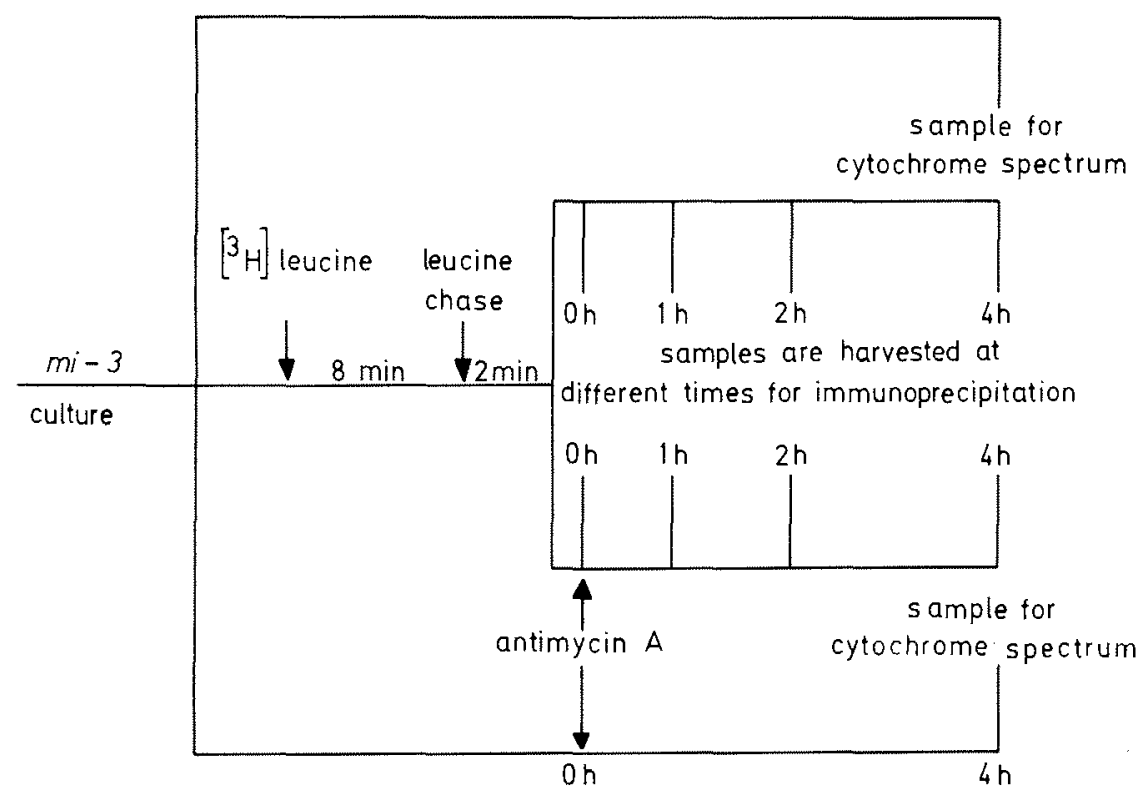

Figure 15. Flow diagram of the experimental procedure applied to mi-3 mutant cells to follow the processing of the cross-reacting mitochondrial product. Additions to the culture are indicated by arrows. For details see text (Werner and Bertrand, 1979). 


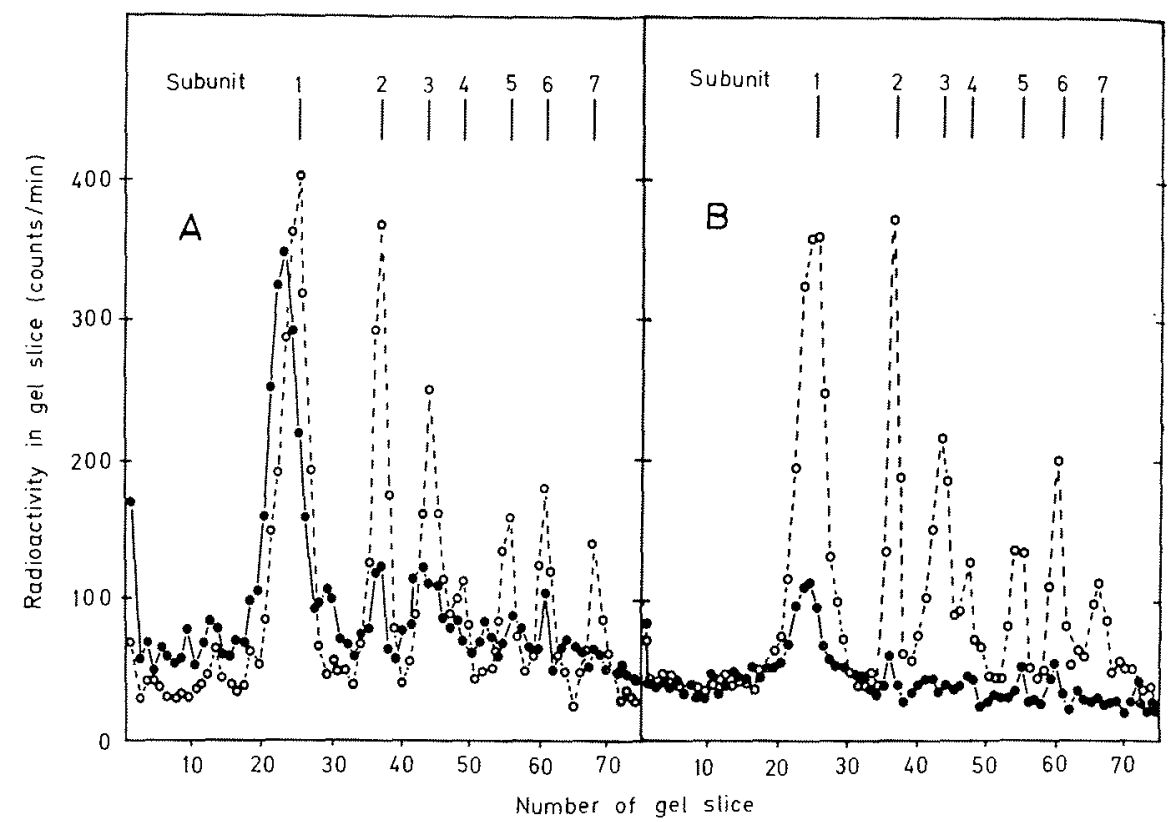

Figure 16. Electrophoretic analysis of polypeptides isolated from the mi-3 mutant by antibodies to subunit 1 of cytochrome oxidase. Cells of $m i-3$ mutant were pulse-labeled ( 8 $\mathrm{min}$ ) by addition of [ $\left.{ }^{3} \mathrm{H}\right]$ leucine to the culture. The pulse-label was chased with unlabeled leucine. Two min after the application of the chase the culture was divided into two portions. One portion was treated with antimycin $A(0.25 \mu \mathrm{g} / \mathrm{ml})$; the other portion was left untreated and the two cultures were incubated further. After various periods of incubation, samples of both cultures were withdrawn, the cells were harvested, and mitochondria were prepared. One portion of each mitochondrial preparation was processed as follows: The protein was solubilized with Triton X-100 and the extract was treated successively with antisubunit 1 immunoglobulin and protein A/Sepharose. Aliquots of the material released from the Sepharose support were mixed with $\left[{ }^{14} \mathrm{C}\right]$ leucine labeled subunits, obtained by immunoprecipitation of cytochrome oxidase from uniformly labeled wild-type cells. The mixtures were subjected to dodecylsulfate gel electrophoresis. The patterns shown are for material isolated from samples harvested (A) immediately after addition of antimycin, (B) after $4 \mathrm{hr}$ of incubation in the presence of antimycin. (-) ${ }^{3} \mathrm{H}$ radioactivity, (O-..) ${ }^{14} \mathrm{C}$ radioactivity.

presence of antimycin. Longer treatment with antibiotic, however, resulted in a dramatic change of the ${ }^{3} \mathrm{H}$-radioactivity pattern. The 45,000 -dalton band shifted to the 41,000 molecular weight position, where the wild-type subunit 1 was found and then the (precipitable) mutant polypeptide disappeared gradually. After $4 \mathrm{hr}$ of incubation in the presence of antimycin, only a small amount of radioactivity could be detected with this antibody (Figure 16B). Spectrophotometric mea- 
surements of these cells revealed that the production of cytochrome oxidase had been induced.

The second portion of each mitochondrial preparation obtained by the procedure described above was first mixed with the wild-type mitochondria isolated from cells labeled uniformly with $\left[{ }^{14} \mathrm{C}\right]$ leucine. The mixture was treated with an antiserum raised against the oxidase subunits 5, 6, and 7 . This antibody does not recognize antigenic determinants of subunit 1 , but the serum is able to precipitate holocytochrome oxidase, if present. Figure 17 A exhibits the labeling pattern of the immunoprecipitate obtained from control cells untreated with antimycin A. Relatively little or no label was detected in the form of distinct peaks at the position of the mitochondrial subunits 1 to 3 . In mutant cells in which cytochrome oxidase had been induced, however, a significant amount of ${ }^{3} \mathrm{H}$-label appeared in a polypeptide correspond-

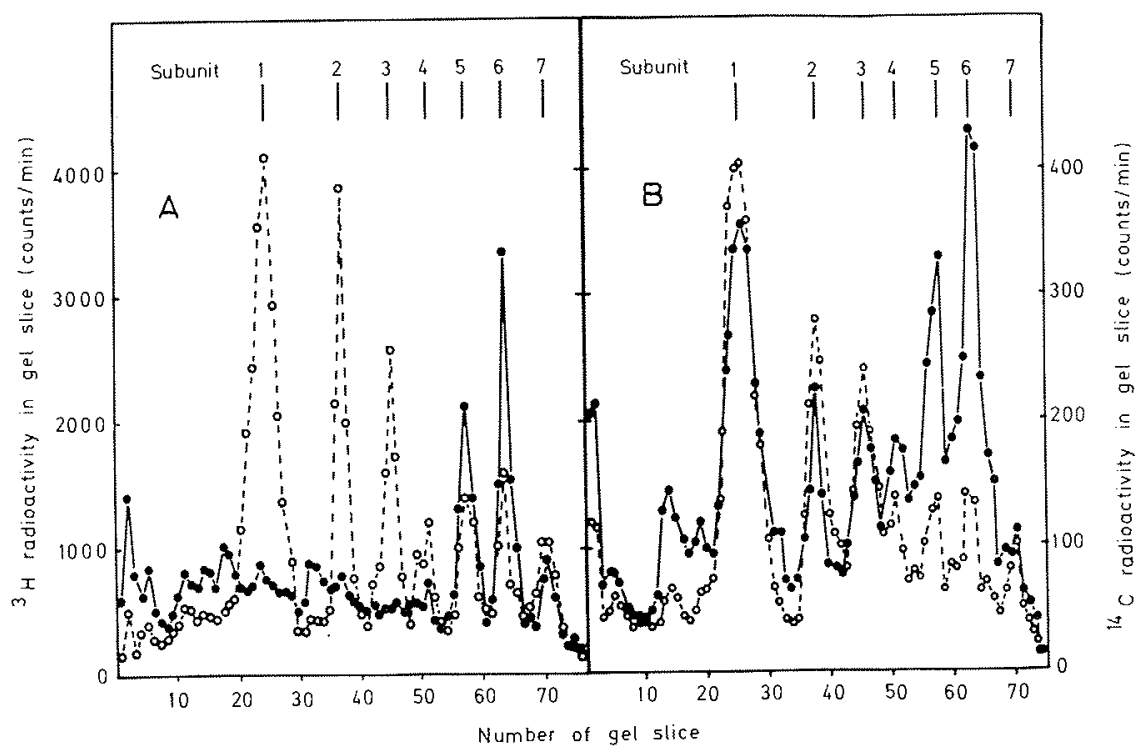

Figure 17. Electrophoretic analysis of polypeptides isolated from the mi-3 mutant by antibodies to subunits 5 to 7 of cytochrome oxidase. The second portion of the mitochondrial preparations, resulting from the procedure described in the legend to Figure 16, was examined in the following way: A preparation was first mixed with wild-type mitochondria prepared from cells labeled uniformly with $\left[{ }^{14} \mathrm{C}\right]$ leucine. The mixture was solubilized with Triton X-100 and treated with an antiserum against subunits 5 to 7 . The immunoprecipitates were dissolved and subjected to dodecylsulfate gel electrophoresis. The patterns shown are for material isolated from samples harvested (A) after incubation in the absence of antimycin (B) after $4 \mathrm{hr}$ of incubation in the presence of antimycin. $\left(\bullet-\bullet{ }^{3} \mathrm{H}\right.$ radioactivity, $\left(\mathrm{O}-\mathrm{O}^{14}{ }^{14} \mathrm{C}\right.$ radioactivity. 
ing to subunit 1 (Figure 17B). It is obvious that this polypeptide was only precipitated by this antiserum because it had become tightly associated with the other enzyme subunits.

In conclusion, we believe that the kinetic data obtained along with the immunological characteristics of the applied antibodies indicate that the 45,000-dalton component represents a larger precursor form of oxidase subunit 1 and that this precursor, after induction of the oxidase formation, is processed to a mature subunit, which is then incorporated into the newly formed oxidase complex.

\section{Identification of Assembly Intermediates of Cytochrome Oxidase}

The isolation of intermediate complexes of the enzyme formation could provide the basis for determining the assembly sequence of the individual oxidase components. Wild-type cells, as well as cytochrome oxidase deficient cells, may be used for the experimental approach. In the latter case, however, one has to consider the possibility that unphysiological intermediates could be studied, which may appear in these cells, so characterized by their inability to accomplish a proper assembly process. An attempt was made to identify intermediate complexes in wild-type cells, although the rapidity of the assembly process occurring in these cells causes considerable problems in the isolation of short-lived complexes. One set of experiments which employ an antibody against subunit 1 of the oxidase is presented to outline the approach with wild-type cells (Werner and Neuner-Wild (1976).

Neurospora wild-type cells were first labeled uniformly with $\left[{ }^{14} \mathrm{C}\right]$ leucine, then pulse-labeled with $\left[{ }^{3} \mathrm{H}\right]$ leucine followed by a chase of unlabeled leucine. Cells were harvested at different times after addition of the tritium label with the application of a rapid filtration and freeze-stop technique. The isolated mitochondria were then treated with the subunit-specific antibody. Figure 18A shows the electrophoretic analysis of a precipitate obtained by the double-immune method. The cells examined had been harvested $4 \mathrm{~min}$ after a pulse-labeling. Three major ${ }^{3} \mathrm{H}$-labeled bands coinciding with marker subunits 1,5 , and 6 of the oxidase were observed (Figure 18A). This is remarkable since the antisubunit $1-\gamma$-globulin does not cross-react with subunits 5 or 6 . Moreover, all three polypeptide components showed the characteristics of precursors: (1) The ${ }^{3} \mathrm{H} /{ }^{14} \mathrm{C}$ ratio calculated for these polypeptides (plotted above Figure 18) exceeded by far the ratio of 2.8 observed for the average cell protein. (2) Most of the ${ }^{3} \mathrm{H}$-radioactivity found in these polypeptide bands was no longer detectable in an immunoprecipitate obtained with mitochondria prepared from cells 


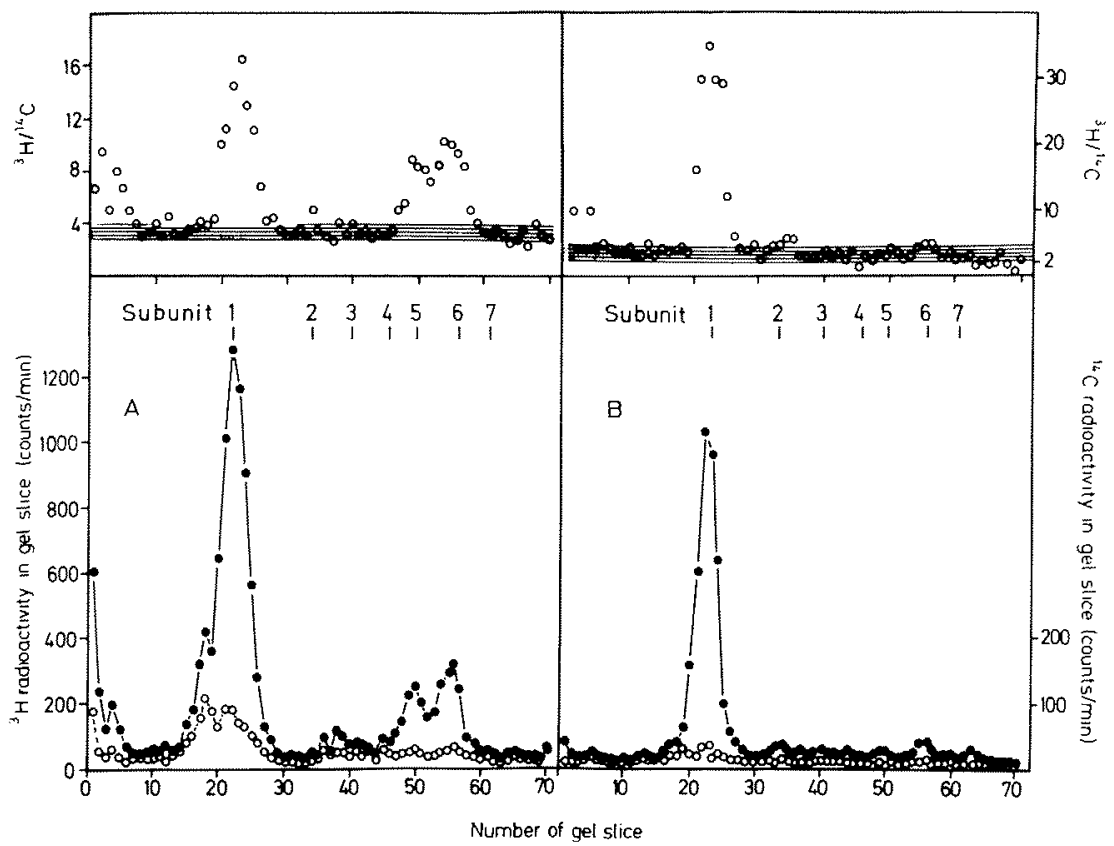

Figure 18. Gel electrophoretic analysis of immunoprecipitates obtained with an antibody to subunit 1 of cytochrome oxidase. Cells were labeled as described in the text. Mitochondria were prepared from cells which were harvested 4 min after pulse-labeling. Mitochondria were solubilized with $100 \mathrm{~m} M$ phosphate buffer- $1 \%$ Triton X-100 containing either $0.3 M \mathrm{KCl}(\mathrm{A})$ or $2 M \mathrm{KCl}(\mathrm{B})$. Then the mixtures were treated with antisubunit $1 \gamma$-globulin from rabbit and antirabbit $\gamma$-globulin from sheep. ${ }^{3} \mathrm{H} /{ }^{14} \mathrm{C}$ ratios of gel slices are given above the radioactivity patterns. The ${ }^{3} \mathrm{H} /{ }^{14} \mathrm{C}$ ratio of total membrane protein was 2.8. (๑-) ${ }^{3} \mathrm{H},(\mathrm{O} \ldots \mathrm{O}){ }^{14} \mathrm{C}$ radioactivity, ${ }^{\circ}{ }^{3} \mathrm{H} /{ }^{14} \mathrm{C}$ ratio (Werner and Neuner-Wild, 1976).

harvested 90 min after addition of $\left[{ }^{3} \mathrm{H}\right]$ leucine (not shown here). The ${ }^{3} \mathrm{H}$-label in these polypeptides was clearly chased by the cold leucine (Werner and Neuner-Wild, 1976).

The above results, together with similar qualitative findings obtained with a specific antibody to subunit 5 (Werner and Neuner-Wild, 1976), suggest that a triplet of precursor polypeptides (consisting of subunits 1,5 , and 6) have formed an incompletely assembled protein complex. The tenet that the three precipitated components have been associated to each other is based on the specificity of the applied antibody directed against one component only. Furthermore, one would expect, if indeed this interpretation is correct, that such an intermediate complex would be rather labile and hence readily dissociable. With this consideration in mind, the effect of different salt concentrations on the dissociation of 
the putative intermediate complex was examined. Figure $18 \mathrm{~B}$ shows the electrophoretic pattern of a precipitate obtained from a mixture of antisubunit 1 immunoglobulin and another sample of the same mitochondrial preparation used for the experiment shown in Figure 18A. Now, however, the solubilized mitochondria had been treated first with $2 M \mathrm{KCl}$ before the antibody was added. This salt concentration does not influence the precipitin reaction per se. The radioactivity pattern (Figure 18B) reveals that only the unassembled subunit 1 , to which the antibody has been directed, was precipitated.

\section{Import of Proteins into the Mitchondria}

\section{A. GENERAL}

A major problem of mitochondrial biogenesis (and organelle biogenesis in general) is the transport of the organelle proteins into or across mitochondrial membranes. What special "entrance signal" controls the translocation of these proteins? There is some evidence that the import of mitochondrial proteins may be regulated in a similar way as the export of secreted proteins in prokaryotic (Wickner, 1979) and eukaryotic cells (Blobel and Dobberstein, 1975a; Blobel and Dobberstein, 1975b; Campbell and Blobel, 1976).

Antibodies directed to specific mitochondrial proteins have been used for the identification of the primary translocation products of cytoplasmically synthesized mitochondrial proteins, as well as for the study of the transfer of these precursors into the organelle. These proteins occur in extremely small amounts and can be identified and analyzed only by means of their labeling with radioactive amino acids. Consequently, for their isolation, either indirect immunoprecipitation techniques (see Sections II.3.C.b and II.3.C.c) or coprecipitations together with substantial amounts of carrier antigens must be applied.

Polypeptides have been synthesized in heterologous systems [wheat germ (Roberts and Paterson, 1973), or reticulocyte (Pelham and Jackson, 1976) systems] in response to isolated RNA from Neurospora and yeast to prevent a processing of newly synthesized proteins by endogenous proteases. However, precursors could also be identified in homologous cell-free systems, either in complete homogenates or in partially reconstituted systems, or even in vivo in whole cells (Korb and Neupert, 1978; Maccecchini et al., 1979; Poyton and Kavanagh 1976).

Since the proteins in question represent only a minimal percentage of the total proteins or the total incorporated radioactivity, contamination of the immunoprecipitates by unspecifically precipitated or adsorbed proteins poses a major technical problem. One means of reduc- 
ing contaminating "background" radioactivity is the application of monospecific antibodies (see Section II.2.B.c). Less contamination was also reached if detergents were present during the immunoprecipitation and during washing of the immunoprecipitates. The antibodies react with the detergent-denatured protein since the antigens have been purified in most cases in the presence of denaturing agents like dodecylsulfate, urea, or guanidine chloride.

\section{B. PRECURSOR OF AN INTRINSIC MEMBRANE PROTEIN: THE ATPASE PROTEOLIPID FROM NEUROSPORA CRASSA}

The ATPase proteolipid can be purified by extracting whole mitochondria with chloroform/methanol. The antibodies raised against the dodecylsulfate-solubilized protein reacted with the proteolipid present in the whole complex (Sebald et al., 1979a), as well as with the isolated polypeptide. A thirty-fold purification of the antibodies was obtained by affinity chromatography (Michel et al., 1979) (see also Section II.2.B.c).

Polyadenylated RNA was isolated from Neurospora crassa by standard procedures (Sheldon et al., 1972). The incorporation rate of $\left[{ }^{3} \mathrm{H}\right]$ leucine or $\left.{ }^{35} \mathrm{~S}\right] \mathrm{methionine}$ into protein by a cell-free system from wheat germ was stimulated ten-fold by the Neurospora RNA $(2.5 \mathrm{OD} / \mathrm{ml}$ incubation mixture). Routinely, $120 \times 10^{6} \mathrm{dpm}$ of $\left[{ }^{3} \mathrm{H}\right]$ leucine was incorporated per ml during a 60 -min period, when $600 \times 10^{6} \mathrm{dpm}$ of $\left[{ }^{3} \mathrm{H}\right]$ leucine was added to $1 \mathrm{ml}$ of incubation mixture.

The whole mixture was processed essentially as detailed by Maccecchini et al. (1979). First, samples were boiled for 2 min in $2 \%$ dodecylsulfate. Four volumes of $2.5 \%$ Triton X-100 and the purified antibodies were added. After $1 \mathrm{hr}$ of incubation at room temperature the solution was clarified either by a 30 -min centrifugation at $244,000 \times \mathrm{g}$ or by a passage through a $0.45 \mu \mathrm{m}$ Millipore filter. Protein A/Sepharose was added either to the filtrate or to the supernatant, and the incubation was continued for another $3 \mathrm{hr}$. The Sepharose was collected by a low-speed centrifugation, washed twice with buffer containing $1 \%$ Triton X-100, twice with $0.1 M$ sodium phosphate, $\mathrm{pH} 8.0$, and once with water. The bound radioactive protein was solubilized with dodecylsulfate (see Section II.3.C.d) or with $80 \%$ formic acid.

About $0.4 \%$ of the total incorporated radioactivity could be recovered from the immunoprecipitate. An amount of 0.8 to $1 \%$ of total radioactivity was obtained when the postribosomal supernatant of the wheat germ system was used as a starting material. This indicates that the newly synthesized antigen recognized by the proteolipid antibodies 
was nearly completely released in soluble form from the wheat germ ribosomes, since about $40 \%$ of the total incorporated radioactivity was found in the postribosomal supernatant.

The immunoprecipitated wheat germ product exhibited a molecular weight of about 12,000 when analyzed by dodecylsulfate gel electrophoresis and subsequent fluorography (Figure 19) or by Bio-Gel P-30 chromatography in the presence of $80 \%$ formic acid. Fewer than $5 \%$ contaminating proteins were detected.

Amino acid sequence studies proved that the mature 8000-dalton proteolipid is part of the 12,000-dalton in vitro product. A mixture of the $\left[{ }^{3} \mathrm{H}\right]$ leucine-labeled precursor and unlabeled mature proteolipid was cleaved with $N$-bromosuccinimide (Wachter and Sebald, 1979). The resulting fragments were submitted to Bio-Gel P-30 chromatography in the presence of $80 \%$ formic acid. A fragment of the proteolipid containing 25 residues was eluted as a well-defined peak together with a fragment of the wheat germ product. An analysis of this fragment by automated solid-phase Edman degradation is shown in Figure 20. The $\left[{ }^{3} \mathrm{H}\right] l e u c i n e$ of the in vitro product was cleaved in

\section{FLUOROGRAPHY OF THE MATURE ATPaSe PROTEOLIPID AND THE PRECURSOR}

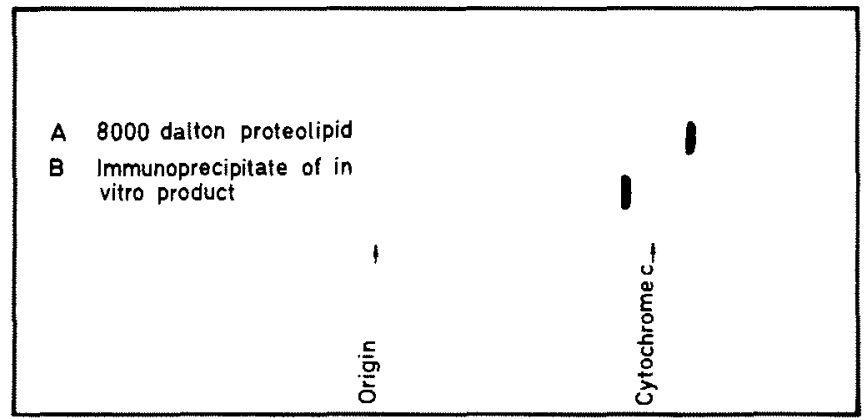

Figure 19. Coelectrophoresis of (A) the authentic ATPase proteolipid and (B) the immunoprecipitate of the in vitro product. (A) $\left[{ }^{3} \mathrm{H}\right]$ leucine labeled proteolipid $\left(4.5 \times 10^{6}\right.$ $\mathrm{dpm} / \mathrm{mg}$ ) was isolated from Neurospora cells grown in the presence of radioactive leucine. (B) A cell-free wheat germ system was incubated for 60 min with poly-A-RNA from Neurospora. Immunoglobulins directed to the ATPase proteolipid (1.25 $\mathrm{mg}$ ) were added and after incubation for $3 \mathrm{hr}$ at room temperature the antigen-antibody complexes were bound to $62.5 \mathrm{mg}$ protein $\mathrm{A} /$ Sepharose. The protein was released from the support by means of $80 \%$ formic acid. The recovered ${ }^{3} \mathrm{H}$-labeled material $\left(3.5 \times 10^{6} \mathrm{dpm}\right)$ amounted to $0.49 \%$ of the total hot acid-insoluble radioactivity present in the incubation mixture. Aliquots of the protein preparations corresponding to $15 \times 10^{3} \mathrm{dpm}$ were analyzed by polyacrylamide gel electrophoresis in dodecylsulfate and by fluorography of the stained gels (Michel et, al., 1979). 


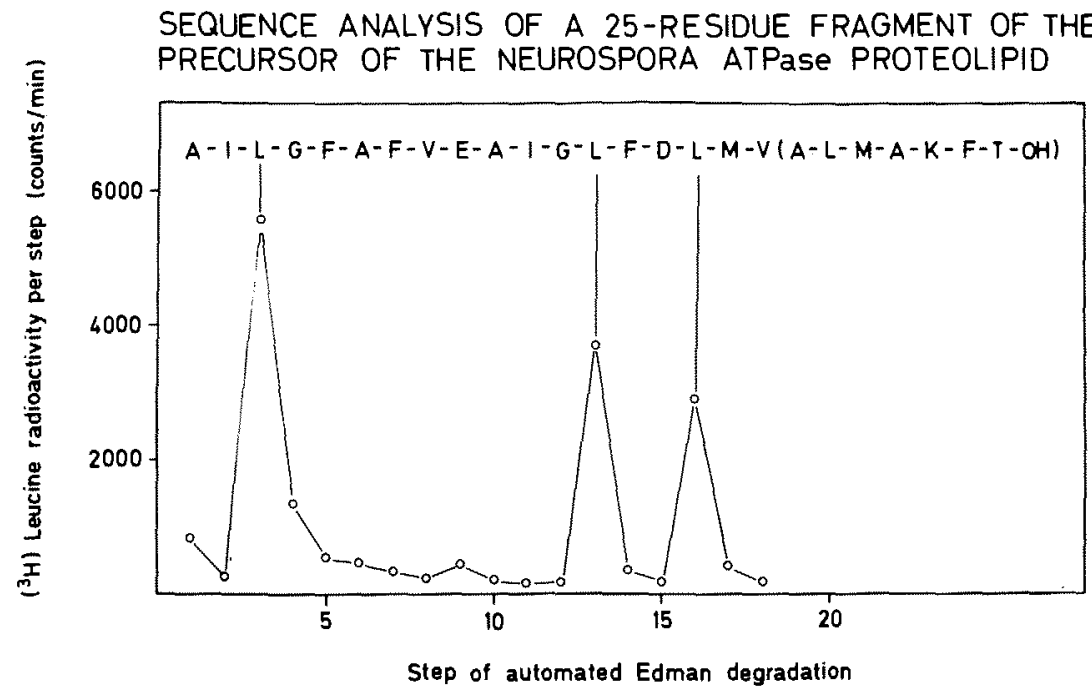

Figure 20. Sequence analysis of a 25-residue fragment obtained from the in vitro product precipitated with the antiproteolipid immunoglobulin. The immunoprecipitate described in the legend to Figure $19\left(1.8 \times 10^{6} \mathrm{dpm}\right)$ was mixed with $1 \mathrm{mg}$ of the authentic proteolipid and cleaved with $N$-bromosuccinimide. The $C$-terminal 25-residue fragment (positions 57 to 81 ) was isolated by chromatography on Biogel P-30 in the presence of $80 \%$ formic acid, coupled to isothiocyanate glass and then submitted to 19 cycles of automated solid-phase Edman degradation. Each cycle was analyzed for the released amino acid, as well as for $\left[{ }^{3} \mathrm{H}\right]$ leucine radioactivity (Michael et. al., 1979).

steps 3,13 , and 16 . The three leucine residues of the authentic proteolipid fragment occur at the same positions. This result, together with the same gel chromatography behavior of the polypeptides, indicates that both fragments are identical.

\section{A PERIPHERAL MEMBRANE PROTEIN FUNCTIONING AT THE OUTER} SURFACE OF THE INNER MITOCHONDRIAL MEMBRANE: BIOSYNTHESIS OF CYTOCHROME $c$ OF Neurospora crassa

The synthesis and intracellular transport of cytochrome $c$ was studied in a homologous cell-free system from Neurospora crassa (Korb and Neupert, 1978). Mature holocytochrome $c$ and heme-free apocytochrome $c$ could be discriminated in the described experiments. This was possible since antibodies raised against apocytochrome $c$ reacted only with the heme-free form of the protein and not with holocytochrome $c$, whereas antibodies directed against holocytochrome $c$ exhibited only a faint reaction with apocytochrome $c$. 
Cell-free homogenates were prepared from cells grown for 10 to 12 $\mathrm{hr}$ in the presence of $250 \mu \mathrm{Ci}$ of [ ${ }^{35} \mathrm{~S}$ ] sulfate/liter (see Section II. I.B.b). One g of cells (wet weight) was mixed with $2 \mathrm{~g}$ of quartz sand and $4 \mathrm{ml}$ of an isotonic sucrose medium, and the slurry was then ground in a mortar. The supernatant obtained upon a 5 -min centrifugation at $3500 \times \mathrm{g}$ was used for the amino acid incorporation studies. After a 10 -min incubation period an incorporation of about $5 \times 10^{6} \mathrm{cpm}{ }^{3} \mathrm{H}$ radioactivity per $\mathrm{ml}$ incubation mixture resulted if 10 nmoles $\left[{ }^{3} \mathrm{H}\right]$ leucine $(50 \mathrm{Ci} / \mathrm{mmole}$ ) were added per $\mathrm{ml}$ homogenate. Incorporation was terminated by cooling the samples to $\mathrm{O}^{\circ} \mathrm{C}$, and mitochondria, microsomes, cytoplasmic ribosomes, and postribosomal supernatant were isolated by differential centrifugation. Triton X-100 was added to the individual cell fractions, and then $10 \mu \mathrm{g}$ of either holocytochrome $c$ or apocytochrome $c$ were mixed as carrier proteins. The fractions were treated with appropriate amounts of the specific immunoglobulins to test for the presence of cell-free translation products.

After the 10-min labeling period, the mitochondrial fraction contained an appreciable amount of newly synthesized holocytochrome $c$, but no apocytochrome $c$. The reverse was found to be true for the postribosomal supernantant. When the labeling period was followed by a 30-min incubation period in the presence of cycloheximide (i.e., in the absence of protein synthesis) the amount of holocytochrome $c$ detected in the mitochondria increased by about $50 \%$, and this increase was balanced by a loss of about $30 \%$ of apocytochrome $c$ observed in the corresponding postribosomal supernatant. Thus, the immunoprecipitated apocytochrome $c$ appears to be a precursor of mitochondrial cytochrome $c$.

These data supply evidence that apocytochrome $c$ is synthesized on cytoplasmic ribosomes and then released into the cytosol. From a cytosolic pool, apocytochrome $c$ is transferred into the mitochondria, where the heme group is covalently linked to the polypeptide. The hypothesis has been rendered that the concomitant conformation change leads to the trapping of the protein to the membrane. In these studies, the apocytochrome $c$ precursor exhibited the same apparant molecular weight as the functional cytochrome $c$.

D. A PERIPHERAL MEMBRANE PROTEIN FUNCTIONING AT THE INNER SURFACE OF THE INNER MITOCHONDRIAL MEMBRANE: BIOSYNTHESIS OF THE MULTISUBUNIT F I $_{1}$-ATPASE OF BAKER'S YEAST

Synthesis and processing of the three large subunits $\left(M_{r}, 58000\right.$, 54000,34000 ) of $F_{1}$-ATPase was studied in a cell-free reticulocyte 
system, in a partially reconstituted system, and in vivo in whole cells (Maccecchini et al., 1979). The newly formed proteins were labeled with $\left[{ }^{35}\right.$ S $]$ methionine.

After amino acid incorporation, samples (usually 0.1 to $1 \mathrm{ml}$ ) were boiled for $3 \mathrm{~min}$ in 2 to $6 \%$ dodecylsulfate and diluted 1:10 with a buffer containing 1\% Triton X-100. Specific antiserums directed against the authentic $F_{1}$-subunits were added in amounts previously determined to be optimal. After a $16-\mathrm{hr}$ incubation at $0^{\circ} \mathrm{C}$, formalinfixed Staphylococcus aureus cells (Kessler, 1975) (twice the antiserum volume of a $10 \%$ suspension) were added, and the suspension was shaken for $1 \mathrm{hr}$ at room temperature. The $S$. aureus cells were washed three times with buffer containing $0.1 \%$ dodecylsulfate and then extracted for $3 \mathrm{~min}$ with $6 \%$ dodecylsulfate at $100^{\circ} \mathrm{C}$. The extracts were analyzed by dodecylsulfate gel electrophoresis. The radioactive bands on the fixed and dried gels were made visible by fluorography (Bonner and Laskey, 1974).

The synthesis of a larger precursor could be detected for all three subunits both in vitro and in vivo. Protein synthesis in a cell-free reticulocyte system was programmed with whole yeast RNA. The antiserum directed against the 58,000-dalton subunit precipitated a polypeptide with a molecular weight of 64,000. Using antiserum against two other enzyme subunits, translation products were obtained with molecular weights which were 2000 and 6000 daltons higher than those of the corresponding mature subunits. Comparison of proteolytic fingerprints (Cleveland et al., 1977) by fluorography of dodecylsulfate gels showed that fragments obtained by partial proteolysis (V8 protease from Staphylococcus aureus) of the mature polypeptide and of the larger precursor were very similar, but not identical. This shows that the precursor not only cross-reacts immunologically with the mature subunit, but that both polypeptides exhibit similar amino acid sequences.

After a 5-min in vivo pulse-labeling of speroblasts only a minor amount of the larger molecular weight precursor was detectable in the immunoprecipitate. The main portion of the immunoprecipitated radioactivity was present in the form of mature subunits. The larger polypeptides disappeared completely if the 5 -min labeling period was followed by a 45-min chase with unlabeled leucine.

The precursors are processed and imported in the mitochondria in the absence of protein synthesis. This was illustrated in the following experiment (Maccecchini et. al., 1979): protein synthesis in the reticulocyte lysate was stopped after $1 \mathrm{hr}$ by adding cycloheximide and by subsequent chilling of the assay. Purified yeast mitochondria were added and the mixture was incubated for another hour at room 
temperature. The mitochondria were pelleted by centrifugation and both the supernatant and the mitochondrial fraction were analyzed for labeled ATPase subunits. The supernatant still contained only the larger forms of the polypeptides, whereas the mitochondrial pellet contained both the larger precursors and the mature forms. Externally added proteases (trypsin and chymotrypsin) degraded the larger forms, but not the mature subunits found in the mitochondria.

These data suggest that the import of these three ATPase subunits into yeast mitochondria does not occur by a vectorial translation. Unlike the vectorial translation of secreted protein in eukaryotic cells (Blobel and Dobberstein, 1975a; Blobel and Dobberstein, 1975b; Campbell and Blobel, 1976), the import of these subunits across both mitochondrial membranes is independent of protein synthesis and it is accompanied by the transient accumulation of discrete precursors in intact cells.

\section{E. REGULATION OF MITOCHONDRIAL PROTEIN SYNTHESIS BY CYTOPLASMIC PRECURSOR PROTEINS}

Mitochondrial protein synthesis in vitro ceases when the endogenous pools of cytoplasmically made proteins are depleted. Studies with isolated yeast mitochondria have been reported (Poyton and Kavanagh, 1976; Poyton and McKemmie, 1976), indicating that an "S-100" supernatant of the cell (homogenate was centrifuged at $100,000 \times \mathrm{g}$ for 30 min) can restore mitochondrial protein synthesis in vitro. When the "S-100" supernatant was titrated with increasing amounts of antiserums directed against holocytochrome oxidase or against the cytoplasmically made enzyme subunits IV and VI, it lost specifically the ability to stimulate the synthesis of mitochondrially made oxidase subunits I, II, and III. Total mitochondrial protein synthesis, however, could still be stimulated.

The immunoprecipitates obtained from radioactively labeled " $\mathrm{S}-100$ " supernantant exhibited upon dodecylsulfate gel electrophoresis a single major peak of radioactivity, displaying an apparent molecular weight of 55,000 . After the 55,000-dalton protein was eluted from gels and its immunological properties were analyzed in Ouchterlony doublediffusion tests against subunit specific antiserums, it was found to cross-react with antiserums against subunits IV and VI, but not with antiserums against subunits I, II, V, or VII. The tryptic peptides prepared from the 55,000-dalton polypeptide were identical with those prepared from a mixture of subunits IV to VII with the exception of four to six additional fragments released from the large polypeptide only. 
The conclusion was drawn that the 55,000 -dalton polypeptide represents a common cytoplasmic precursor for all four of the cytoplasmically made subunits IV to VII of cytochrome oxidase. At the moment, the observation that the radioactivity of the 55,000-dalton polypeptide decreased only slightly during a chase with unlabeled amino acids remains unexplained.

\section{Identification of Mitochondrial mRNA and of Mitochondrial Structural Genes}

In principle, the informational content of $m$ RNA or DNA can be identified by the immunological isolation of translation products formed in cell-free systems programmed with isolated $m$ RNA or DNA. In the case of mitochondrial nucleic acids, this approach has failed, to date, insofar as only incomplete small-sized products could be synthesized in contrast to the expected larger authentic polypeptides. Immunologically it could be established, however, that the small in vitro products observed include sufficient antigenic determinants of authentic mitochondrial gene and translation products.

Total mitochondrial RNA $(0.7 \mathrm{mg} / \mathrm{ml})$ from yeast stimulated fiftyfold the incorporation of $\left.{ }^{35} \mathrm{~S}\right]$ methionine by cell-free extracts of $E$. coli (Moorman et al., 1976; Moorman et al., 1978). Short (apparent molecular weight 12,000 ) hydrophobic polypeptides were formed displaying a high tendency to aggregate. Antiserums directed against the mitochondrially made subunits I, II, and III of yeast cytochrome oxidase precipitated 7 to $12 \%$ of the incorporated radioactivity in double-immunoprecipitation tests. Unlabeled cytochrome oxidase added to the assay competed specifically with the small translation products in the immune reaction. Components of the mitochondrial ATPase complex also appear to be among these in vitro products, since an antiserum raised against the whole enzyme complex resulted in a weak but consistently positive immunoprecipitation.

To identify the mRNA specifying the synthesis of subunits of cytochrome oxidase or ATPase, the $m t$ RNA was fractionated by sedimentation in isokinetic sucrose gradients. The individual fractions were assayed for their ability to synthesize products containing antigenic determinants of cytochrome oxidase and ATPase subunits. Translation products reacting with an antiserum against subunits I and II of cytochrome oxidase (27\% of the total translation products) were formed by fractions of $m$ RNA sedimenting in the $11 \mathrm{~S}$ region. Synthesis of ATPase protein was detectable using two species of $m$ RNA: the bulk of the activity was observed in the $6 \mathrm{~S}$ fraction, and a minor activity was 
associated with the fraction contributing to the heavy side of the $12 \mathrm{~S}$ peak present in the absorbance profile.

The genes for the 11S RNA species have been localized on the physical map of Saccharomyces cerevisiae mitochondrial DNA by hybridization to restriction fragments, using the techniques described by Southern (1975). The position of these genes corresponds roughly to the oxi- 1 and oxi-3 loci as mapped by genetic studies.

The cell-free system from Escherichia coli was also highly active in the linked transcription-translation assay using yeast mitochondrial DNA from both wild-type and respiratory-deficient petite strains (Moorman et al., 1978). The products of protein synthesis were short hydrophobic polypeptides $\left(M_{r}<10,000\right)$, which showed a high tendency to aggregate. As mentioned above, products with the same properties were obtained when protein synthesis was programmed with yeast RNA. The results of indirect immunoprecipitation tests suggested that antigenic determinants of cytochrome oxidase were among the products synthesized. The in vitro products were identified immunologically by a slightly modified procedure of van Zaane et al. (1975).

\section{CONCLUSIONS AND IMPLEMENTATIONS}

The examples selected in this chapter document that specific antibodies are indispensable tools in studies of the biogenesis of mitochondria. The extreme sensitivity of immunological techniques makes possible the detection and isolation of polypeptides present only in trace amounts. Investigations of the assembly process of multisubunit enzymes, of the import and processing of mitochondrial protein, and of the identification of $m$ RNA involved in the synthesis of mitochondrial protein, depend completely on the sensitivity of specific antibodies.

The potential of present immunological techniques, however, has not yet been fully exploited for studies of mitochondrial biogenesis. Future developments can benefit from methods developed and applied in other areas, such as virology, hematology, and tumor cell research.

In principle, the specificity of the immunoglobulins allows a differentiation of different forms of a polypeptide. As discussed in Section III.4, different antigenic sites of subunit 3 of cytochrome oxidase are exposed in the free precursor polypeptide and in the subunit present in the whole enzyme complex. The specificity of the antiserums raised according to conventional methods in rabbits, however, is not under strict control of the investigator. The use of monoclonal hybrid cell lines, on the other hand, may make possible the production of homogeneous monospecific antibodies (Galfre et al., 1977). Such an- 
tibodies would be extremely useful for research on the assembly of multisubunit enzymes.

Sequence analysis of immunoprecipitated radioactive precursors has only been started in the case of mitochondrial proteins. This is in contrast to secreted eukaryotic and prokaryotic proteins from which considerable information on the amino acid sequences of the so-called "signal peptides" of preproteins is already available. These amino terminal extensions of the polypeptides appear to determine the transport of the protein across a membrane (Blobel and Dobberstein, 1975a; Blobel and Dobberstein, 1975b; Campbell and Blobel, 1976). The intriguing problem, whether all of the imported mitochondrial proteins contain presequences, and if so, whether these presequences are identical or at least similar, or whether different classes of these proteins (e.g., matrix proteins, integral and peripheral membrane proteins) exhibit different features for their translocation, remains unsolved.

At the moment, no information is available on the $m$ RNA species directing the synthesis of imported mitochondrial proteins. These ribonucleic acids can possibly be isolated by immunoprecipitation of nascent polypeptide chains associated with polysomes (Schütz et al., 1977; Groner et al., 1977). This technique has led to the isolation of several $m$ RNA species including that of albumin.

Specific antibodies have been applied for the identification of eukaryotic genes cloned and expressed in Escherichia coli. Specific translation products produced by the bacterial cell could be detected by a radioimmunoassay (Miles, 1977). A plastic sheet coated with antibody molecules is exposed to lysed bacteria so that a released antigen can bind. The immobilized antigen is then labeled with radioiodinated antibodies. A few molecules of antigen are sufficient to generate an adequate signal (Broome and Gilbert, 1978; Villa-Komaroff et al., 1978). Another method for the identification of specific DNA sequences cloned in $E$. coli is provided by hybrid-arrested translation (Paterson et al., 1977). A homologous DNA hybridized to $m$ RNA prevents the translation of a polypeptide, which then is no longer immunoprecipitated by specific antibodies. These techniques also may allow the isolation of structural genes which program the synthesis of mitochondrial proteins.

\section{ABBREVIATIONS}

IgG, immunoglobulin $\mathrm{G}$,

DCCD, dicyclohexylcarbodiimide,

TRIS, tris (hydroxymethyl) aminomethan,

MOPS, $N$-morpholinopropanesulfonic acid, 


\section{Acknowledgment}

The authors wish to thank R. Zauner, M. L. Everett, E. Beese and I. Dortmund for valuable help during the preparation of the manuscript. This research was supplied by grants from the Deutsche Forschungsgemeinschaft.

\section{References}

Axén, R., Porath, J., and Ernback, S. (1967), Nature (Lond.), 214, 1302-1304.

Bertrand, H. and Collins, R. A. (1978), Molec. gen. Genet., 166, 1-13.

Bertrand, H. and Werner, S. (1977), Eur. J. Biochem., 79, 599-606.

Bertrand, H. and Werner, S. (1979), Eur. J. Biochem., 98, 9-18.

Bertrand, H., Szakacs, N. A., Nargang, F. E., Zagozeski, C. A., Collins, R. A., and Harrigan, J. C. (1976), Can. J. Genet. Cytol., 18, 397-409.

Blobel, G. and Dobberstein, B. (1975a), J. Cell Biol., 67, 835-851.

Blobel, G. and Dobberstein, B. (1975b), J. Cell Biol., 67, 852-862.

Bonner, W. M. and Laskey, R. A. (1974), Eur. J. Biochem., 46, 83-88.

Brautigan, D. L., Ferguson-Miller, S., and Margoliash, E. (1978), in Methods in Enzymology (S. Fleischer and L. Packer, Eds.), Vol. LIII, Academic Press, New York and London, pp. $128-164$.

Broome, S. and Gilbert, W. (1978), Proc. Natl. Acad. Sci. USA, 75, 2746-2749.

Bruckmooser, K. and Werner, S. (1976), in Genetics and Biogenesis of Chloroplasts and Mitochondria (Th. Bücher et al., Eds.), Elsevier/North-Holland Biomedical Press, Amsterdam, pp. 253-258.

Buetow, D. E, and Wood, W. M. (1978), in Subcellular Biochemistry (D. B. Roodyn, Ed.), Vol. 5, Plenum, New York, pp. 1-85.

Cabral, F., Solioz, M., Rudin, Y., and Schatz, G. (1978), J. Biol. Chem., 253, 297-304.

Campbell, P. N. and Blobel, G. (1976), FEBS Lett., 72, 215-226.

Cattell, K. J., Lindop, C. R., Knight, I. G., and Beechey, R. B. (1971), Biochem. J., 125, $169-177$.

Chua, N. H. and Blomberg, F. (1979), J. Biol. Chem., 254, 215-223.

Cleveland, D. W., Fischer, S. G., Kirschner, M. W., and Laemmli, U. K. (1977), J. Biol. Chem., 252, 1102-1106.

Converse, C. A. and Papermaster, D. S. (1975), Science, 189, 469-472.

Cullen, S. E. and Schwartz, B. D. (1976), J. Immunol., 117, 136-142.

Fan, H. and Mueller-Lantzsch, N. (1976), J. Virol., 18, 401-410.

Fleischer, A. and Packer, L. Eds. (1978), Methods in Enzymology, Vol. LIII, Academic Press, New York and London.

Forsgren, A. and Sjöquist, J. (1966), J. Immunol., 97, 822-827.

Galfre, G., Howe, S. C., Milstein, L., Butcher, G. W., and Howard, J. C. (1977), Nature (London), 266, 550-552.

Groner, B., Hynes, N. E., Sippel, A. E., Jeap, S., Chi Nguyen Hun, M., and Schütz, G. (1977), J. Biol. Chem., 252, 6666-6674.

Hallermayer, G., Zimmermann, R., and Neupert, W. (1977), Eur. J. Biochem., 81, 523-532. 
Helenius, A. and Simons, K. (1975), Biochim. Biophys, Acta, 415, 29-79.

Hjelm, H., Hjelm, K., and Sjöquist, J. (1972), FEBS Lett., 28, 73-76.

Jackl, G. and Sebald, W. (1975), Eur. J. Biochem., 54, 97-106.

Jagow, v. G., Weiss, H., and Klingenberg, M. (1973), Eur. J. Biochem., 33, 140-157.

Jagow, v. G., Schägger, H., Riccio, P., Klingenberg, M., and Kolb, H. J. (1977), Biochem.

Biophys. Acta, 462, 549-558.

Jagow, v. G., Schägger, H., Engel, W. D., Machleidt, W., Machleidt, I., and Kolb, H. J. (1978), FEBS Lett., 91, 121-215.

Jonsson, S. and Kronvall, G. (1974), Eur. J. Immunol., 4, 29-33.

Kessler, S. W. (1975), J. Immunol., 115, 1617-1624.

Kessler, S. W. (1976), J. Immunol., 117, 1482-1490.

Klein, J. L., Edwards, D. L., and Werner, S. (1975), J. Biol. Chem., 250, 5852-5858.

Korb, H. and Neupert, W. (1978), Eur.J. Biochem., 91, 609-620.

Kronvall, G. and Williams, R. C. (1969), J. Immunol., 103, 828-833.

Laurell, C. B. (Ed.) (1972), Scand.J. Clin. Lab. Invest., 29, Suppl. 124.

Maccecchini, M. L., Rudin, Y., Blobel, G., and Schatz, G. (1979), Proc. Natl. Acad. Sci. USA, 76, 343-347.

Mancini, G., Carbonara, A. O., and Heremans, J. F. (1965), Immunochemistry, 2, 235-254.

Michel, R., Wachter, E., and Sebald, W. (1979), FEBS Lett., 101, 373-376.

Miles, L. E. M. (1977), in Handbook of Radioimmunoassay (G. E. Abraham, Ed.), Dekker, New York, pp. 131-177.

Mitchell, M. D., Mitchell, H. K., and Tissieres, A. (1953), Proc. Natl. Acad. Sci. USA, 39, 606-613.

Moorman, A. F. M., Lamie, F., and Grivell, L. A. (1976), FEBS Lett., 71, 67-72.

Moorman, A. F. M., Grivell, L. A., Lamie, F., and Smits, H. L. (1978), Biochim. Biophys. Acta, 517, 351-365.

Moorman, A. F. M., Van Ommen, G. J.-G., and Grivell, L. A. (1978), Molec. gen. Genet,, $160,13-24$.

Nargang, F. E., Bertrand, H., and Werner, S. (1978), J. Biol. Chem., 253, 6364-6369.

Nargang, F. E., Bertrand, H., and Werner, S. (1979), Eur. J. Biochem., 102, 297-307.

Ouchterlony, O. (1958), Progr. Allergy, 5, I-12.

Paterson, B. M., Roberts, B. E., and Kuff, E. L. (1977), Proc. Natl. Acad. Sci. USA, 74, 4370-4374.

Pelham, H, R. B. and Jackson, R. J. (1976), Eur. J. Biochem., 67, 247-256.

Peterson, E. A. and Sober, H. A. (1956), J. Am. Chem. Soc., 78, 751-755.

Poyton, R. O. and Kavanagh, J. (1976), Proc. Natl. Acad. Sci. USA, 73, 3947-3951.

Poyton, R. O. and McKemmie, E. (1976), Genetics and Biogenesis of Chloroplasts and Mitochondria (Th. Bücher et al., Eds.), Elsevier/North-Holland Biomedical Press, Amsterdam, pp. 207-214.

Riccio, P., Aquilla, H., and Klingenberg, M. (1975), FEBS Lett., 56, 133-138.

Ries, G., Hundt, E., and Kadenbach, B. (1978), Eur.J. Biochem., 91, 179-191.

Roberts, B. E. and Paterson, B. M. (1973), Proc. Natl. Acad. Sci. USA, 70, 2330-2334.

Ruoslahti, E. (Ed.) (1976), Scand, J. Immunol, Supplement No. 3.

Schütz, G., Kieval, S., Groner, B., Sippel, A. E., Kurtz, D. T., and Feigelson, P. (1977), Nucleic Acids Res., 4, 71-84. 
Schwab, A. J. (1973), Thesis, University of Munich.

Schwab, A. J., Sebald, W., and Weiss, H. (1972), Eur. J. Biochem., 30, 511-516.

Sebald, W. (1977), Biochem. Biophys. Acta, 463, I-27.

Sebald, W. and Wild, G. (1979), Methods Enzymol., 55, 344-35 I.

Sebald, W., Schwab, A. J., and Bücher, Th. (1969), FEBS Lett., 4, 243-246.

Sebald, W., Weiss, H., and Jackl, G. (1972), Eur, J. Biochem., 30, 413-4I7.

Sebald, W., Machleidt, W., and Otto, J. (1973), Eur. J. Biochem., 38, 31 1-324.

Sebald, W., Graf, T., and Lukins, H. B. (1979a), Eur. J. Biochem., 93, 587-599.

Sebald, W., Werner, S., and Weiss, H. (1979b), Methods Enzymol., 56, 50-58.

Sheldon, R., Jurale, C., and Kates, J. (1972), Proc. Natl. Acad. Sci. USA, 69, 417-421.

Sierra, M. F. and Tzagoloff, A. (1973), Proc. Natl. Acad. Sci. USA, 70, 3155-3159. Sober, H. A., Gutter, F. J., Wyckoff, M. M., and Peterson, E. A. (1956), J. Am Chem. Soc., 78
756-763.

Southern, E. M. (1975), J. molec. Biol., 98, 503-517.

Van Zaane, D., Gielkens, A. L. J., Dekker-Michielsen, M. J. A., and Bloemers, H. P. J. (1975 Virology, 67, 544-552.

Villa-Komaroff, L., Efstratiadis, A., Broome, S., Lomedico, P., Tizard, R., Naber, S. P., Chick W. L., and Gilbert, W. (1978), Proc. Natl. Acad. USA, 75, 3727-3731.

Wachter, E. and Sebald, W. (1979), Eur. J. Biochem., submitted.

Weiss, H. (1972), Eur. J. Biochem., 30, 469-478.

Weiss, H. (1976), Biochim. Biophys. Acta, 456, 291-313.

Weiss, H. and Juchs, B. (1978), Eur. J. Biochem., 88, 17-28.

Weiss, H. and Ziganke, B. (1974), Eur. J. Biochem., 41, 63-7I.

Weiss, H., Sebald, W., and Bücher, Th. (1971), Eur. J. Biochem., 22, 19-26.

Welsch, K. J., Dorvall, G., and Wigzell, H. (1975), Nature (Lond.), 254, 67-69.

Werner, S. (1974), Eur. J. Biochem., 43, 39-48.

Werner, S. and Neuner-Wild, M. (1976), in Genetics and Biogenesis of Chloroplasts and Mitochond? (Th. Bücher, W. Neupert, W. Sebald, and S. Werner, Eds.), North-Holland Biomedical Press. Amsterdam, pp. 199-206.

Werner, S. and Machleidt, W. (1978), Eur. J. Biochem., 90, 99-105.

Werner, S. and Bertrand, H. (1979), Eur. J. Biochem., 99, 463-470.

Werner, S., Schwab, A. J., and Neupert, W. (1974), Eur. J. Biochem., 49, 607-617.

Wickner, W. (1979), Annual Rev. Biochem., 48, 23-45. 